Research Article

\title{
Optimization of the Influencing Variables on the Corrosion Property of Steel Alloy 4130 in 3.5 wt.\% NaCl Solution
}

\author{
A. M. El-Shamy $\mathbb{D}^{1}{ }^{1}$ M. A. El-Hadek $\mathbb{D}^{2},{ }^{2}$ A. E. Nassef, ${ }^{2,3}$ and R. A. El-Bindary $\mathbb{D}^{2}$ \\ ${ }^{1}$ Physical Chemistry Department, Electrochemistry and Corrosion Laboratory, National Research Centre, El-Buhouth St. 33, \\ Dokki, PO 12622, Giza, Egypt \\ ${ }^{2}$ Production and Mechanical Design Engineering Department, Faculty of Engineering, Port-Said University, \\ Port-Said 42523, Egypt \\ ${ }^{3}$ High Institute of Engineering and Technology, North Sinai, El-Arish 45511, Egypt
}

Correspondence should be addressed to R. A. El-Bindary; ra.bindary@yahoo.com

Received 3 February 2020; Revised 5 March 2020; Accepted 14 March 2020; Published 14 April 2020

Academic Editor: Pedro M. Mancini

Copyright (c) 2020 A. M. El-Shamy et al. This is an open access article distributed under the Creative Commons Attribution License, which permits unrestricted use, distribution, and reproduction in any medium, provided the original work is properly cited.

\begin{abstract}
In this work, the aqueous Lawsonia inermis extract (LI) is investigated as an economic and green deterioration inhibitive formula for steel alloy 4130 in $3.5 \mathrm{wt} . \% \mathrm{NaCl}$ solutions. The water-based extraction process is considered as one of the cheapest techniques for preparation of active ingredients of natural products. These ingredients play an important role in corrosion mitigation of steel alloy 4130 in saline media. This extract was subjected to three different parameters: inhibitor concentration, rotation speed, and temperature in $3.5 \mathrm{wt} . \% \mathrm{NaCl}$ solutions. The electrochemical techniques are used to perceive the corrosion behavior, and the obtained results were dedicated to theoretical explorations to assess the features of corrosion inhibition and the adsorption over the steel substrate in $3.5 \mathrm{wt} . \% \mathrm{NaCl}$ solutions. Affording to the electrochemical techniques of LI showed very promising results against corrosion depending on the inhibitor concentrations. The inhibition efficiency of LI was additionally appraised at three diverse temperatures, and the results disclosed that the inhibition efficiency is decreased. Additionally, the theoretical aspects illuminated that the main active ingredients of LI have a proclivity to coagulate on the steel substrates allowing these areas to paradigm a protecting layer on the steel surfaces. This behavior is in provision of investigational results. Statistical studies were used to examine the consequence of chief constraints (i.e., inhibitor concentration, temperature, and rotation speed) on the inhibition efficiency and the rate of corrosion of steel alloy 4130. The inhibitive effect of LI in contradiction of the corrosion of steel alloy 4130 surfaces is considered by resources of DFT/6-31G(d) calculations. The quantum chemical parameters interrelated to the inhibition efficiency are considered.
\end{abstract}

\section{Introduction}

Currently, 3.5 wt.\% $\mathrm{NaCl}$ solutions are commonly utilized in various investigations due to the broad-spectrum existence in industrial zones [1]. It is well known that this medium is considered as an unpleasant medium which strictly deteriorates the metals and alloys, generating growth of more stable layers by direct attack with the surrounding constituents [2,3]. Consequently, the unfavorable deterioration procedure conveys approximately severe cost through the energy loss and failure of metallic structures. Throughout current years, emerging approaches for shielding of metals in contradiction of decomposition have been a significant area of exploration. Generally, corrosion inhibitors are the greatest common and economic technique for monitoring the corrosion of metals against aggressive chloride media [4-7]. It has been verified that the organic compounds including atoms such as $\mathrm{N}, \mathrm{O}, \mathrm{P}$, and $\mathrm{S}$ in extra exist in aromatic rings and binary or tripartite bonds. All these factors can make the organic molecule to act as efficient corrosion inhibitors. Unfortunately, utmost of these inhibitors display poisonous action in contradiction to the environment [8-12]. The green chemistry has been speedily developed to diminish the antagonistic possessions 
accompanying with the toxic organic inhibitors. Natural products are commonly used to get the alternative source for the toxic compounds. Diverse fragments of natural products have been earlier laboring and used for monitoring the deterioration of metallic substrate. Based on the source and the mode of action, the safe and green chemicals are obtainable in the formulae of biopolymeric forms or in the form of ionic liquids [13]. The Pedalium murex $L$ extract is used to protect the steel surface in pickling electrolyte and conveyed an efficacy of about $89 \%$ [14]. With a concentration of about $1000 \mathrm{ppm}$, it shows an inhibition efficiency of about $93 \%$ for protection of mild steel in acidic solution [15]. In addition, the optimum concentration of Salvia officinalis alcoholic extract was applied to protect of the carbon steel in an acidic solution with inhibition efficiency of about $87 \%$ [16]. The leaf extract of Cinnamomum verum is used to protect mild steel in acidic environment with an inhibition efficiency of about 93.1\% [17]. The inhibition efficiency of $5 \mathrm{~g} / \mathrm{l}$ from Akee apple seed extract was investigated for controlling the decomposition of the steel in a medium of $\mathrm{HCl}$ and experimentally reported the inhibition efficiency of about $86.9 \%$ [18]. The Achyranthes aspera extract was used to protect mild steel in an acidic medium with $90 \%$ inhibition efficiency [19]. The root of Glycyrrhiza glabra is applied as green corrosion inhibitor with 99\% inhibition efficiency after immersion of steel coupon for $72 \mathrm{~h}$ in $3.5 \mathrm{wt} . \% \mathrm{NaCl}$ solution. In case of $800 \mathrm{ppm}$ from leaves of Glycyrrhiza glabra, the inhibition efficiency is decreased to $88 \%$ after immersion of mild steel in acidic medium for $24 \mathrm{~h}$ [20]. In case of $300 \mathrm{ppm}$ of Musa paradisiaca extract, the inhibition efficiency is reported to be $82 \%$ in acidic solution [21]. The peel extract of Musa paradisiaca was reported to be $89 \%$ in acidic medium after $24 \mathrm{~h}$ immersion [22]. At the present time, several factors play an important role in assortment of a corrosion inhibitor for the application like efficiency, cost effective, availability, and ecological impact must be considered. Additionally, water solubility of corrosion inhibitors is a significant representative in their abstraction procedure. In case of abstraction of the safe and green corrosion monitoring compounds with partially soluble in water, an extra solvent should be used but not recommended because it is not safe and executes undesirable ecological possessions. Water extract is very an important part from environmentally friendly aspects since the procedure depends on water which is more cost-effective if equated with other solvents. Corrosion is one of the main factors for the degradation of an engineering structure in marine environments, occurring due to chemical or electrochemical reactions between the marine environment and metals. Numerous curricula of organic composites are extensively applied for controlling the metallic corrosion in acidic atmospheres [23-27]. Investigational resources are convenient in explaining the mode of action of inhibition process; nonetheless, these techniques are frequently none economic and wasting time. Continuing computer-based techniques have been used for controlling the use of hypothetical understanding in the study of corrosion monitoring. Accordingly, several techniques such as quantum chemistry and molecular modeling have been achieved to associate the inhibiting performance to the molecule's property of LI $[28,29]$. Application of hypothetical parameter shows two chief compensations: (i) the mixtures with their several parts of substituents can be categorized by their molecular structures; (ii) the planned mode of action of interface can be attributed for the reactivity of chemical compounds [30-33]. By bearing in mind these aspects, the present study was planned to use the aqueous Lawsonia inermis extract (LI), which is cost-effective, for monitoring the decomposition of mild steel alloy 4130 in $3.5 \mathrm{wt} . \% \mathrm{NaCl}$ solutions. Lawsonia inermis extract comprises organically active mixtures with biological and medical values and potential corrosion inhibitor for metallic substrates. The electrochemical techniques were used to calculate the inhibition efficiency of the inhibitor. The morphology after exposure in $3.5 \mathrm{wt} . \% \mathrm{NaCl}$ solutions of steel alloy 4130 surfaces was analyzed without and with gradual concentrations of green inhibitor. The optimum conditions among the variable parameters (i.e., concentration of inhibitor, rotation speed, and temperature) which effect on the corrosion rates and inhibition efficiencies were tested by utilization of investigational arithmetical enterprise (Box-Behnken). Additionally, the theoretical assessments were studied for the adsorption landscapes of the investigated compound over the steel alloy 4130 substrate and their reactive sites. Remarkable found that the oxygen containing compound, which promotes more inhibiting activity, is among diverse ingredients of LI.

\section{Materials and Methods}

\subsection{Materials}

2.1.1. Steel Alloy 4130. Inhibition possessions of Lawsonia inermis extract (LI) were inspected on the steel alloy 4130 electrode $(1 \mathrm{~cm} \times 1 \mathrm{~cm})$ with composition as mentioned in Table 1. The electrodes were graceful using SiC papers (several grades). The refined sample was washed away with bidistilled water and formerly dried out. The destructive 3.5 wt. $\% \mathrm{NaCl}$ solutions protected by LI at several concentrations were equipped by $\mathrm{NaCl}$ (Merck Co.) and bidistilled water.

2.1.2. Lawsonia inermis Extract (LI) Preparation. Water has been commonly employed as an appropriate solvent for abstraction of inhibitor from the dried Lawsonia inermis powder. Water is used a proper solvent for the two main reasons: (i) make the extraction process cost-effective and environmentally acceptable; (ii) only the water-soluble components can be extracted from Lawsonia inermis during the water extraction process. These complexes do not demonstrate good controlling rate in destructive media. $100 \mathrm{~g} / 100 \mathrm{ml}$ distilled water of Lawsonia inermis powder was poured into $1000 \mathrm{ml}$ beaker, boiled for $30 \mathrm{~min}$, and then filtered, and the filtrate is concentrated to $100 \mathrm{ml}$. The resulting clear solution was then used for preparation of the examination electrolytes in electrochemical studies. The major existing compound in LI is 2-hydroxy-1,4-napthoquinone (HNQ; lawsone). Lawsone is the standard natural 
TABLE 1: Chemical analysis of steel alloy 4130 used in the present study ${ }^{\mathrm{a}}$.

\begin{tabular}{lcccccccc}
\hline Element & $\mathrm{C}$ & $P$ & $\mathrm{~S}$ & $\mathrm{Mn}$ & $\mathrm{Si}$ & $\mathrm{Mo}$ & $\mathrm{Cr}$ & $\mathrm{Fe}$ \\
\hline$\%$ & $0.28-0.33$ & 0.035 & 0.04 & $0.4-0.6$ & $0.2-0.35$ & $0.15-0.25$ & $0.8-1.1$ & Rem \\
\hline
\end{tabular}

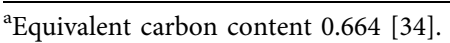

dye delimited at $1.0-1.4 \%$ in the leaves of LI (Henna) [35]. Figure 1 represents the chemical structures of lawsone that is the main component in the aqueous extract of LI [36].

\subsection{Methods}

2.2.1. Electrochemical Techniques. A GILL AC expedient fortified with gill analyst software was working for EIS tests. The value of frequency was between 0.01 and $10,000 \mathrm{~Hz}$. Also, the $Z$ view software package was castoff for the examination of impedance results. Electrochemical assessments were performed in a common three electrodes including working (steel alloy 4130), counter (platinum), and reference electrode $(\mathrm{Ag} / \mathrm{AgCl})$.

2.2.2. Statistical Analysis. For studying the corrosion rate and inhibition efficiency of steel alloy 4130 using of LI as inhibitor, Box-Behnken experimental design $[37,38]$ for the variables (concentration of inhibitor, rotation speed, and temperature) is shown in Table 2. The response variables were developed by designs of the rejoinder superficial outlines and the greatest analytical replicas. The Box-Behnken enterprise can accept the subsequent prototypical formula [39]:

$$
E(y)=\beta_{0} \sum_{i=1}^{3} \beta_{i} X_{i}+\sum_{i=1}^{3} \sum_{j=1}^{3} \beta_{i j} X_{i} X_{j}
$$

where $y$ is the rejoinder adjustable estimation, $X_{\mathrm{i}}$ are the autonomous parameters (inhibitor load, rotation speed, and temperature) that are recognized for each experimental run, and $\beta_{0}, \beta_{\mathrm{i}}$, and $\beta_{\mathrm{ij}}$ are the worsening limits. Software package, Design-Expert 6.1, Stat-Ease, Inc., Minneapolis, USA, was used for regression examination of investigational statistics and to design rejoinder superficial. The statistical parameters were subjected to approximate the variance analysis (ANOVA). The amount of appropriate investigational consequences to the polynomial prototypical calculation was articulated to determinate the coefficient, $R^{2}$.

2.2.3. Theory and Computational Details. The DFT method was used to optimize the molecular structure of the investigated compound. The optimization of the total structure together with the vibrational analysis is implementing by revenue of Gaussian 03 package [40]. The molecule was assembled by means of the Gauss View 3.0 instigated in Gaussian 03 package. The adsorption centers of the inhibitor molecule were predicted using frontier molecular orbitals (HOMO and LUMO). Intended for the modest transmission of electrons, the adsorption must happen at the portion of the fragment anywhere the gentleness, $\sigma$, has the maximum

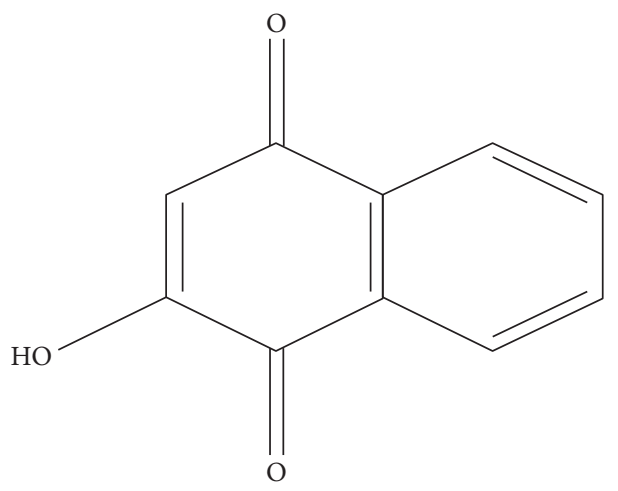

FIgURE 1: Structure of lawsone (central component) in Lawsonia inermis.

rate. Rendering to Koopman's theory, the $E_{\mathrm{HOMO}}$ and $E_{\text {LUMO }}$ of the corrosion inhibiter formula are connected to the potential of ionization (I) and the affinity of electron (A), correspondingly [41]. The extraquantum parameters of the inhibitor formula that bounce appreciated data about the responsive performance are ionization potential (IP), electron affinity (EA), electronegativity $(\chi)$, chemical potential $(\mu)$, hardness $(\eta)$, and softness $(\sigma)$. These parameters were designed by the subsequent formula:

$$
\begin{aligned}
& I=-E_{\mathrm{HOMO}}, \\
& A=-E_{\mathrm{LUMO}}, \\
& \mu=-\chi, \\
& \mu=\frac{\left(E_{\mathrm{HOMO}}+E_{\mathrm{LUMO}}\right)}{2}, \\
& \eta=\frac{\left(E_{\mathrm{LUMO}}-E_{\mathrm{HOMO}}\right)}{2} .
\end{aligned}
$$

The softness $(\sigma)$ is the converse of the universal stiffness and calculated as follows:

$$
\sigma=\frac{1}{\eta}
$$

The optimization of lawsone compound displayed in Figure 1 was theoretically achieved applying density functional theory (DFT) to measure their electronic possessions. To recognize these atoms, the possible protonated site including $\mathrm{O}$ and $\mathrm{C}$ atoms with binary bonds (Figure 1) was primary protonated. These protonated molecules were calculated using DFT performance. Subsequently, the subsequent protonated fragments with augmented arrangements and the ethics of protonation affinity (PA) and basicity (B) were examined [42-45]. 
TABLe 2: Corrosion rate and inhibition efficiency of steel alloy 4130 in $3.5 \mathrm{wt} \% \mathrm{NaCl}$ using LI as an inhibitor.

\begin{tabular}{|c|c|c|c|c|c|c|c|}
\hline $\begin{array}{l}\text { Run } \\
\text { number }\end{array}$ & $\begin{array}{l}\text { Conc. of inhibitor } \\
(\%)\end{array}$ & $\begin{array}{l}\text { Rotation speed } \\
\quad(\mathrm{rpm})\end{array}$ & $\begin{array}{c}\text { Temperature } \\
\left({ }^{\circ} \mathrm{C}\right)\end{array}$ & $\begin{array}{c}\text { Thrust } \\
\text { pressure }(\mathrm{Pa})\end{array}$ & $\begin{array}{l}\text { Total } \\
\text { time }(\mathrm{s})\end{array}$ & $\begin{array}{l}\text { Corrosion rate } \\
(\mathrm{mL} / \mathrm{Y})\end{array}$ & $\begin{array}{l}\text { Inhibition efficiency } \\
(\%)\end{array}$ \\
\hline 1 & 5 & 150 & 50 & 101325 & 1200 & 23.9 & 50.51 \\
\hline 2 & 10 & 150 & 50 & 101325 & 1200 & 5.2 & 89.23 \\
\hline 3 & 5 & 250 & 50 & 101325 & 1200 & 28.7 & 49.47 \\
\hline 4 & 10 & 250 & 50 & 101325 & 1200 & 6.7 & 88.20 \\
\hline 5 & 5 & 200 & 25 & 101325 & 1200 & 14.9 & 64.18 \\
\hline 6 & 10 & 200 & 25 & 101325 & 1200 & 4.1 & 90.14 \\
\hline 7 & 5 & 200 & 75 & 101325 & 1200 & 39.3 & 42.54 \\
\hline 8 & 10 & 200 & 75 & 101325 & 1200 & 15.3 & 77.63 \\
\hline 9 & 7.5 & 150 & 25 & 101325 & 1200 & 4.97 & 87.72 \\
\hline 10 & 7.5 & 250 & 25 & 101325 & 1200 & 5.89 & 86.71 \\
\hline 11 & 7.5 & 150 & 75 & 101325 & 1200 & 12.51 & 69.12 \\
\hline 12 & 7.5 & 250 & 75 & 101325 & 1200 & 14.43 & 65.31 \\
\hline 13 & 7.5 & 200 & 50 & 101325 & 1200 & 9.66 & 76.77 \\
\hline 14 & 7.5 & 200 & 50 & 101325 & 1200 & 9.66 & 76.77 \\
\hline 15 & 7.5 & 200 & 50 & 101325 & 1200 & 9.66 & 76.77 \\
\hline 16 & 7.5 & 200 & 50 & 101325 & 1200 & 9.66 & 76.77 \\
\hline 17 & 7.5 & 200 & 50 & 101325 & 1200 & 9.66 & 76.77 \\
\hline
\end{tabular}

Blank corrosion rate: $150 \mathrm{rpm}=40.5 \mathrm{mpy} ; 200 \mathrm{rpm}=41.6 \mathrm{mpy}$; and $250 \mathrm{rpm}=44.3 \mathrm{mpy}$.

\section{Results and Discussion}

\subsection{Electrochemical Measurements}

3.1.1. Open Circuit Potential. Open circuit potential (OCP) magnitudes were examined for the steel alloy 4130 substrate during immersion in 3.5 wt.\% $\mathrm{NaCl}$ media with diverse LI loads, and the outcomes are offered in Figure 2. Rendering to Figure 2, the OCP of the steel alloy 4130 sampling after immersion in $3.5 \mathrm{wt} . \% \mathrm{NaCl}$ solutions speedily declined and touched a steady rate after $200 \mathrm{~s}$. The disbanding of oxide layer $[46,47]$ and the adsorption particles on the substrate of steel alloy 4130 are the foremost explanations for the detected OCP weakening [48-50]. It is well-known that by growing the period of immersion and the LI concentration the OCP values turn out to be more negative, approving the role of foremost cathodic inhibition of the LI. It is also originated that the most negative values of OCP were present in solution injected by $10 \%$ of LI, demonstrating the adsorption of LI composites on the steel surface.

\subsubsection{Electrochemical Impedance Spectroscopy.} Investigation of electrochemical impedance spectroscopy (EIS) was finished to examine the LI inhibition ability on the steel alloy 4130 electrode in $3.5 \mathrm{wt}$ \% $\mathrm{NaCl}$ solutions. Nyquist diagrams for steel alloy 4130 electrodes engrossed in the saline solutions that are threatened by diverse LI concentrations that are assumed in Figure 3 authorize a modest capacitive circlet for all trials, closefitting that the leading governing response at the boundary of steel surface and 3.5 wt.\% $\mathrm{NaCl}$ solutions is charge transmission. The loop of capacitance with abundant superior width can be detected in the Nyquist plots of the electrolytes comprising 10\% LI compared to the uninhibited solution [51]. In the occurrence of LI inhibitor, a great capacitive loop gives the impression in the electrolyte of low-slung frequency assortment. Figure 4 illustrates the operation of a modest prototypical $R(R Q)$ as

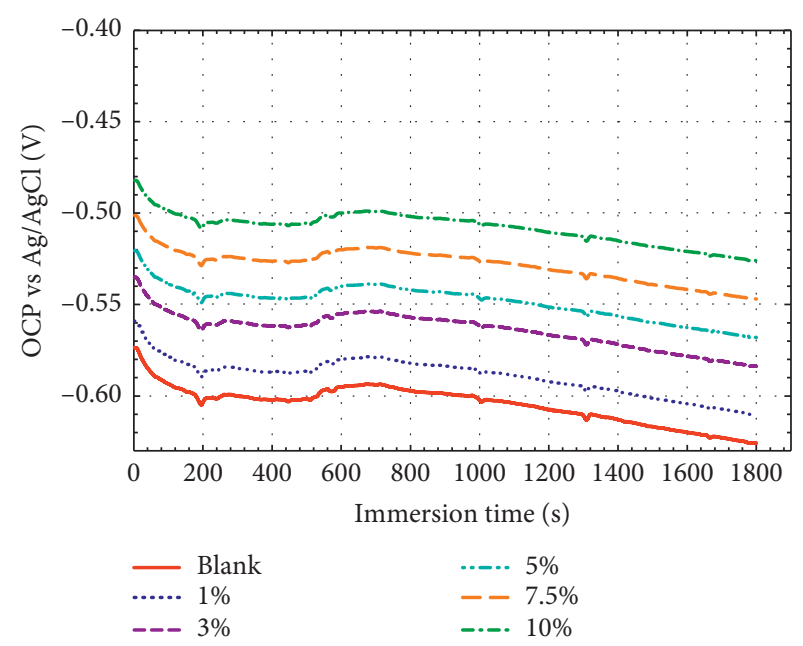

Figure 2: Open circuit potential vs. time of steel alloy 4130 sample engrossed in $3.5 \mathrm{wt} . \% \mathrm{M} \mathrm{NaCl}$ media and diverse loads of LI.

exemplified in Figure 3 and the corresponding analogous circuit. The impedance conspiracies were form fitting, and the limits obtained are exposed in Table 3. Solitary remark of one-time continual in the Nyquist designs of the reserved trial announces that the constant period which associated with the double layer is determined at a small range of the frequency and protected layer at growth frequency variety. Consequently, in the used model, $R_{\mathrm{s}}, R_{t}$, and $C P_{E t}$ are correspondingly revealing the solution resistance, total resistance $\left(R_{t}\right.$ charges transfer resistance $\left(R_{c t}\right)+$ inhibitor film resistance $\left(R_{f}\right)$ ), and the total constant phase element. The efficiency $(\eta \%)$ principles of LI in $3.5 \mathrm{wt} \% \mathrm{NaCl}$ solutions on steel alloy 4130 surface were intended by means of entire resistance $\left(R_{t}\right)$ stated as follows:

$$
\eta \%=\left[\left(R_{t}^{i}-\frac{R_{t}^{0}}{R_{t}^{i}}\right)\right] \times 100,
$$




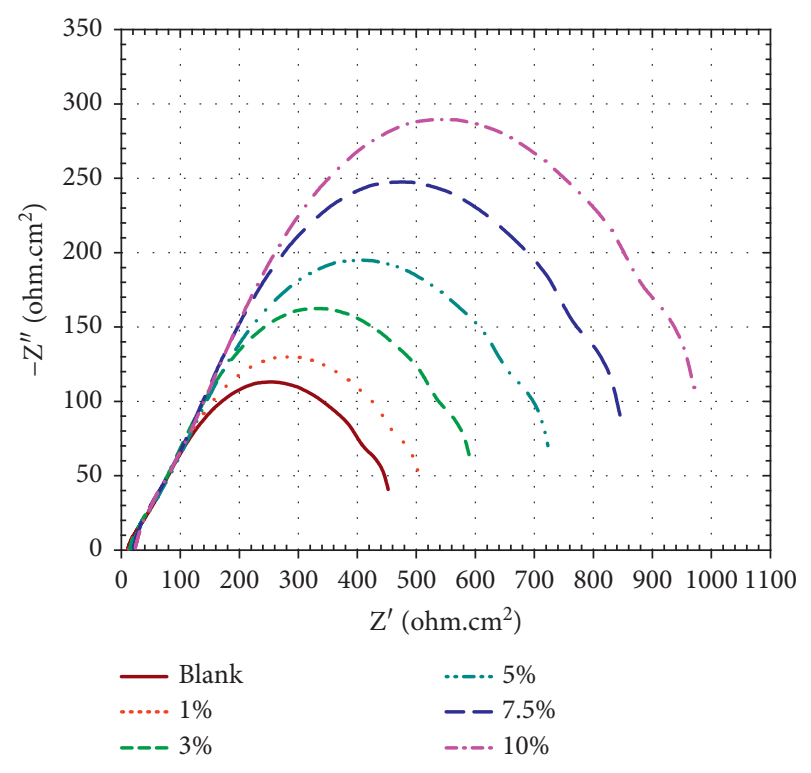

Figure 3: Nyquist plots for the steel alloy 4130 sample engrossed in 3.5 wt.\% $\mathrm{NaCl}$ electrolyte and diverse loads of LI.

where $R_{t}^{i}$ and $R_{t}^{0}$ are the total resistance in the occurrence and nonattendance of LI, correspondingly.

The whole resistance is the totality of solution resistance and charge transfer resistance [52-54]. The calculated ethics of efficacy are tabularized in Table 3. According to Table 3, with growth in the LI concentration, the efficiency and $\mathrm{R}_{t}$ values expressively enlarged. The supreme productivity was got for the protected solution by $10 \%$ of aqueous extract of LI. The better $R_{t}$ morals theme to the growth of shielding coat development on the surface of steel alloy 4130 [55]. Concluding the subsequent equation [56], the total capacitance $\left(C_{t}\right)$ parameter, representative of the reduction or growth of the resident dielectric constant, thinness of the double layer, and the adsorption of inhibitor layer [57], was considered and conveyed in Table 3:

$$
c_{t}=Y_{0, t}^{1 / n} \times\left(\frac{R_{s} R_{t}}{R_{s}+R_{t}}\right)^{(1-n) / n} .
$$

The compact $C_{t}$ that principles as an outcome addition of inhibitor load can be ascribed to the decrease in resident dielectric width and the argument of electrolyte fragments with inhibitor composites at the boundary of steel alloy 4130/3.5 wt.\% $\mathrm{NaCl}$ [58].

\subsubsection{Potentiodynamic Polarization Test Results.} Potentiodynamic polarization designs of the steel alloy 4130 trials uncovered to the $3.5 \mathrm{wt} . \% \mathrm{NaCl}$ solutions together with LI are exemplified in Figure 5. Numerous electrochemical constraints such as cathodic Tafel slopes $\left(\beta_{c}\right)$, corrosion potential $\left(E_{\text {corr }}\right)$, and corrosion current density $\left(i_{\text {corr }}\right)$ are gotten from the extrapolation process of Tafel plot, and the consequences are conserved in Table 4. It is expressed that, in the anodic designs of the protected steel alloy $4130 \mathrm{ex}-$ amples, no visible anodic Tafel region is undescribed and

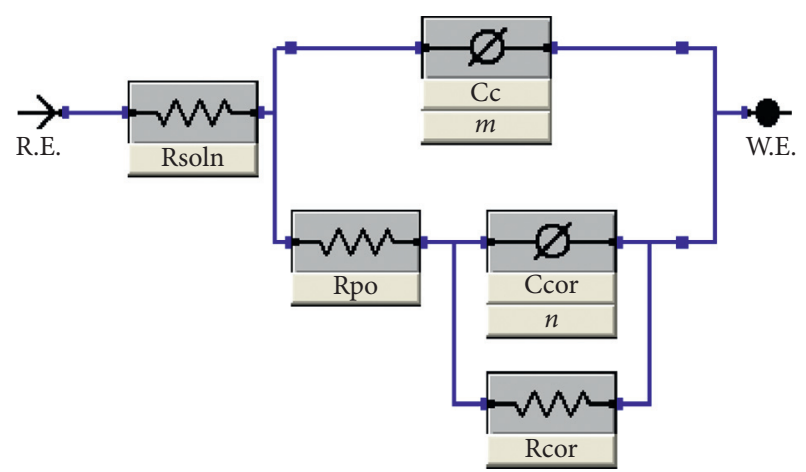

FIgURE 4: Electrochemical equivalent circuit simulated for steel alloy 4130 sample engrossed in 3.5 wt.\% $\mathrm{NaCl}$ electrolyte and diverse loads of LI.

TABLE 3: The electrochemical impedance parameters of steel alloy 4130 sample occupied in $3.5 \mathrm{wt} . \% \mathrm{NaCl}$ solution with diverse loads of LI.

\begin{tabular}{lcccccc}
\hline $\begin{array}{l}\text { Medium, } \\
\%\end{array}$ & $\begin{array}{c}R_{\mathrm{s}} \\
\left(\Omega \mathrm{cm}^{2}\right)\end{array}$ & $\begin{array}{c}\text { Yo } \\
\left(\mathrm{Fcm}^{2}\right)\end{array}$ & $n$ & $\begin{array}{c}R_{\mathrm{p} 1} \\
\left(\Omega \mathrm{cm}^{2}\right)\end{array}$ & $\begin{array}{c}R_{\mathrm{p} 2} \\
\left(\Omega \mathrm{cm}^{2}\right)\end{array}$ & $\mathrm{L} / \mathrm{H}$ \\
\hline Blank & 0.593 & $5.2 \times 10^{-4}$ & 30.60 & 2.587 & 1.186 & 7.188 \\
1 & 0.642 & $5.1 \times 10^{-4}$ & 0.37 & 3.791 & 1.806 & 7.562 \\
3 & 1.150 & $6.8 \times 10^{-4}$ & 0.55 & 8.395 & 3.467 & 7.972 \\
5 & 1.663 & $7.7 \times 10^{-4}$ & 0.65 & 14.006 & 5.405 & 14.926 \\
7.5 & 2.387 & $7.2 \times 10^{-4}$ & 0.71 & 19.321 & 6.961 & 17.877 \\
10 & 3.682 & $8.4 \times 10^{-4}$ & 1.01 & 35.609 & 11.99 & 26.748 \\
\hline
\end{tabular}

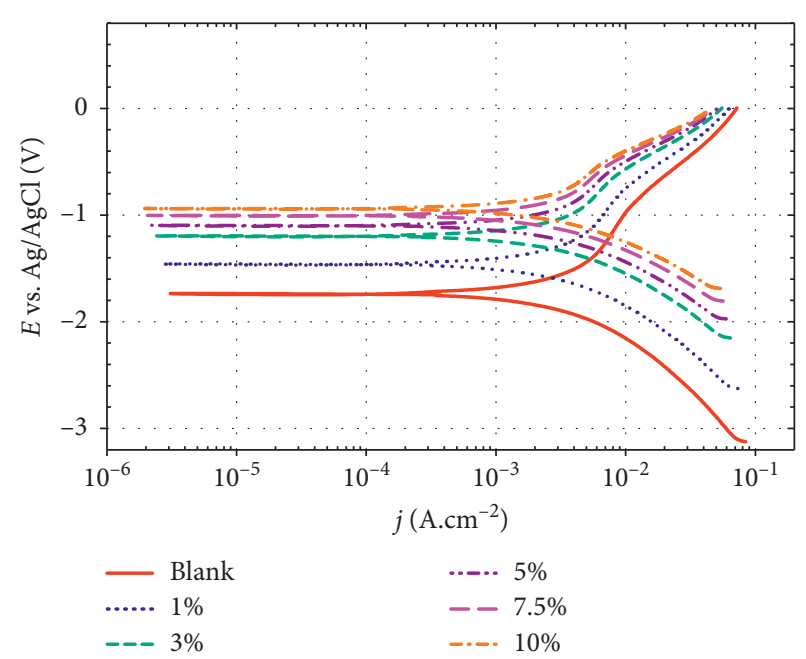

Figure 5: Potentiodynamic polarization designs of steel alloy 4130 sample engrossed in $3.5 \mathrm{wt} . \% \mathrm{NaCl}$ solution and diverse loads of LI.

deliberated as the anodic concepts of the Tafel slope $(\beta c)$. It is clearly noticed that, as in Figure 5, the current density of both anodic and cathodic twigs significantly condensed in the occurrence of LI extracts [59]. Nevertheless, the extra effect of LI on the current density of cathodic branch, since it reduced and the move of $E_{\text {corr }}$ to extra negative magnitudes, proves that the LI represented as a cathodic inhibitor rather than an anodic one. Observing the equivalent cathodic 
TABLE 4: Tafel constraints obtained from polarization curves from Tafel extrapolation technique of steel alloy 4130 trial immersed in 3.5 wt. $\%$ $\mathrm{NaCl}$ medium and diverse loads of LI.

\begin{tabular}{|c|c|c|c|c|c|c|c|}
\hline \multirow{2}{*}{ Medium (\%) } & \multicolumn{7}{|c|}{ Parameters } \\
\hline & $\mathrm{B}_{c}\left(\mathrm{mV} \mathrm{dec}^{-1}\right)$ & $E_{\text {corr }}(\mathrm{mV})$ & $j_{\text {corr }}\left({ }_{\mu A \mathrm{~cm}}{ }^{-2}\right)$ & $\mathrm{B}_{a}\left(\mathrm{mV} \operatorname{dec}^{-1}\right)$ & $R_{p}\left(\Omega \mathrm{cm}^{2}\right)$ & $R_{\text {corr }}\left(\mathrm{mmy}^{-1}\right)$ & IE (\%) \\
\hline Blank & -102.96 & -614 & 3145 & 224.86 & 154.3 & 44.4 & - \\
\hline 1 & -127.17 & -605 & 3033 & 89.18 & 5.57 & 32.6 & 26.57 \\
\hline 3 & -121.07 & -576 & 2887 & 84.89 & 5.3 & 21.7 & 51.13 \\
\hline 5 & -118.13 & -562 & 2817 & 82.83 & 5.17 & 15.6 & 64.86 \\
\hline 7.5 & -113.09 & -538 & 2697 & 79.3 & 4.95 & 10.2 & 77.03 \\
\hline 10 & -109.09 & -519 & 2601 & 76.45 & 4.77 & 4.8 & 89.19 \\
\hline
\end{tabular}

shapes through the minor slope variation specifies that LI inhibited the cathodic reaction deprived of altering the hydrogen development mechanism [60].

The provided data in Table 4 establish that the corrosion current density and corrosion potential constraints dropped in contradiction of an upsurge in LI concentration. This remark authenticates the actual inhibitive achievement of the LI on the drop of steel alloy 4130 corrosion mostly over the cathodic reaction conquest. The effect of LI on the anodic outlet figure clearly validates the fragments of inhibitor which interrelated through the energetic anodic spots and altered the steel alloy 4130 corrosion mechanism. The cations of steel produced throughout the anodic disbanding of steel alloy 4130 can vary developments with the organic particles of LI. The empty orbital of steel cations can receive the free lone pair of electrons of oxygen heteroatoms, which exist in the structure of inhibitor. Accordingly, the LI particles settle on the anodic spots and guard the steel from unembellished disbanding. At small loads, the coverage surface is imperfect, hence diminution of $i_{\text {corr }}$ with an upsurge in the inhibitor load, foremost to the upsurge in superficial coverage of the corrosion inhibitor [61].

\subsection{Statistical Analysis}

3.2.1. Optimization of the Experimental Conditions. To optimize the three individual factors (inhibitor concentration, rotation speed, and temperature), there were a total of 17 experimental runs in the Box-Behnken design (Table 2).

3.2.2. Corrosion Rate. Figure 6 shows the contour plot of the consequence of inhibitor concentration and rotation speed on the corrosion rate of steel alloy 4130 at different temperatures 25,50 , and $75^{\circ} \mathrm{C}$. It is clear that, at $25^{\circ} \mathrm{C}$, the corrosion rate was decreased from 12.44 to $3.47 \%$ with an increasing inhibitor concentration from 5 to $10 \%$. Also, the effect of increasing rotation speed from 150 to $250 \mathrm{rpm}$ indicates no effect. By increasing temperature to 50 and/or $75^{\circ} \mathrm{C}$, the corrosion rate decreases with increasing inhibitor concentration and insignificant effect with rotation speed (Figure 6). Figure 7 shows the contour plot of the consequence of inhibitor concentration and temperature on the corrosion rate of steel alloy 4130 at different rotation speeds 150,200 , and $250 \mathrm{rpm}$. It is clear that, at $150 \mathrm{rpm}$, the corrosion rate was decreased from 14.14 to $5.10 \%$ with increasing inhibitor concentration from 5 to $10 \%$. Also, increasing temperature from 25 to $75^{\circ} \mathrm{C}$ decreases the corrosion rate from 6.75 to $8.66 \%$, indicating no effect. By increasing rotation speed to 200 and/or $250 \mathrm{rpm}$, the corrosion rate has insignificant effect with increasing inhibitor concentration and temperature (Figure 7). Figure 8 shows the contour plot of the consequence of rotation speed and temperature on the corrosion rate of steel alloy 4130 at different concentrations of inhibitors $5,7.5$, and $10 \%$. It is clear that, at $5 \%$, the corrosion rate was increased from 16.23 to $35.40 \%$ with increasing temperature from 25 to $75^{\circ} \mathrm{C}$. Also, increasing inhibitor concentration from 5 to $10 \%$ indicates no effect. By increasing inhibitor concentration to 7.5 and/or $10 \%$, the corrosion rate decreases.

Figure 9 shows the 3D plot of corrosion rate of steel alloy 4130 as a function of inhibitor concentration and rotation speed at different temperatures 25,50 , and $75^{\circ} \mathrm{C}$. It shows that, at $25^{\circ} \mathrm{C}$, the maximum corrosion rate was $18.67 \mathrm{~mL} / \mathrm{Y}$. Also, increasing the temperature from 50 to $75^{\circ} \mathrm{C}$ increases the maximum corrosion rate to 27.58 and $38.68 \mathrm{~mL} / \mathrm{Y}$, respectively.

Figure 10 shows the $3 \mathrm{D}$ plot of the consequence of temperature and inhibitor load on the deterioration rate of steel alloy 4130 at different rotation speeds 150, 200, and $250 \mathrm{rpm}$. It shows that, at $150 \mathrm{rpm}$, the maximum corrosion rate was $34.13 \mathrm{~mL} / \mathrm{Y}$. Also, increasing the rotation speed from 200 to 250 shows insignificant increase in the maximum corrosion rate to 37.59 and $38.57 \mathrm{~mL} / \mathrm{Y}$, respectively [62].

Figure 11 shows the $3 \mathrm{D}$ plot of corrosion rate of steel alloy 4130 as a function of rotation speed and temperature at different inhibitor concentration 5, 7.5, and $10 \%$. It shows that, at $5 \%$, the maximum corrosion rate was $32.71 \mathrm{~mL} / \mathrm{Y}$. Also, increasing the inhibitor concentration from 7.5 to $10 \%$ decreases the maximum corrosion rate to 13.67 and $10.23 \mathrm{~mL} / \mathrm{Y}$, respectively.

All the investigational data, composed of the $3 \mathrm{D}$ cubic, as publicized in Figure 12, exposed that the corrosion rate which fluctuated from 4.49 to $38.57 \mathrm{~mL} / \mathrm{Y}$ can be produced. The lowest corrosion rate, $4.49 \mathrm{~mL} / \mathrm{Y}$, can be obtained at high concentration of inhibitor and small stages of temperature and rotation speed. On the contrary, the highest corrosion rate can be achieved at low concentration of inhibitor and high levels of temperature and rotation speed. However, increasing the concentration of inhibitor leads to decrease in the corrosion rate which is desirable. This is attributed to the LI inhibitor, which is well known as inhibiting agent, since it is stable at $<50^{\circ} \mathrm{C}$ and $150 \mathrm{rpm}$. Figure 13 displays the normal 


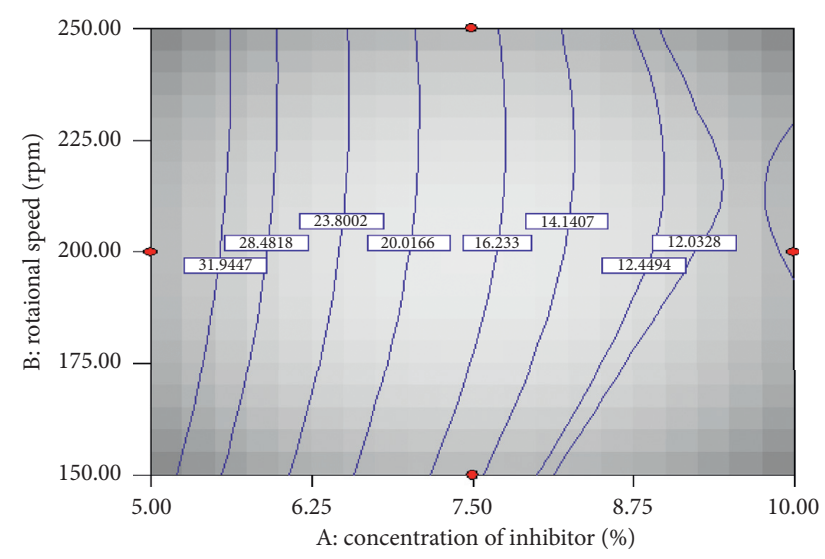

(a)

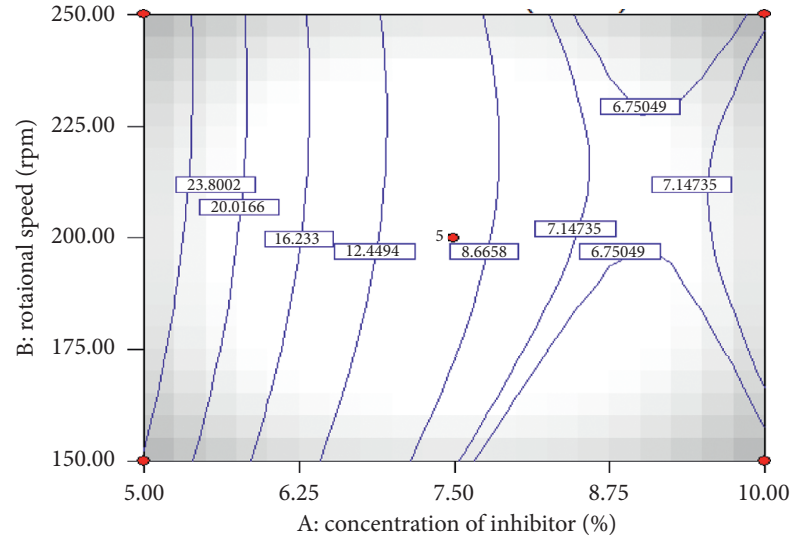

(b)

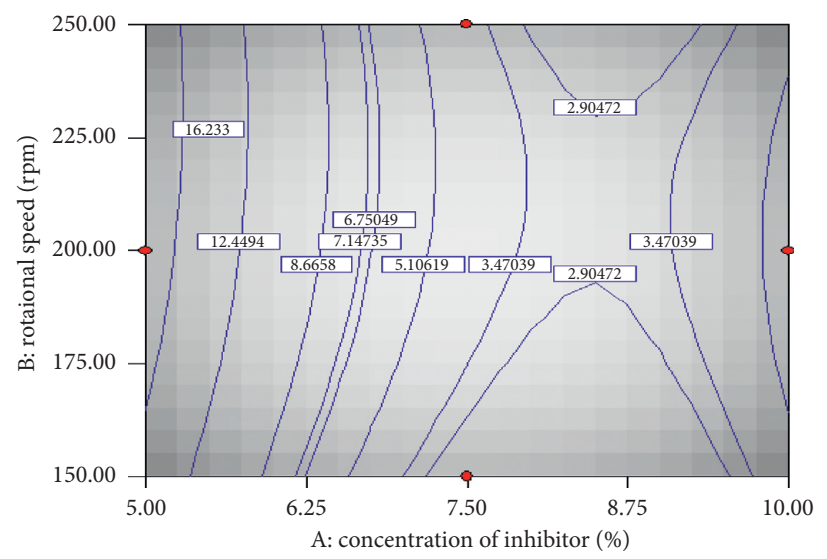

(c)

FIGURE 6: Contour plot of corrosion rate as a purpose of inhibitor load and rotational speed at the temperatures (a) $75^{\circ} \mathrm{C}$, (b) $50^{\circ} \mathrm{C}$, and (c) $25^{\circ} \mathrm{C}(\mathrm{mL} / \mathrm{Y})$.

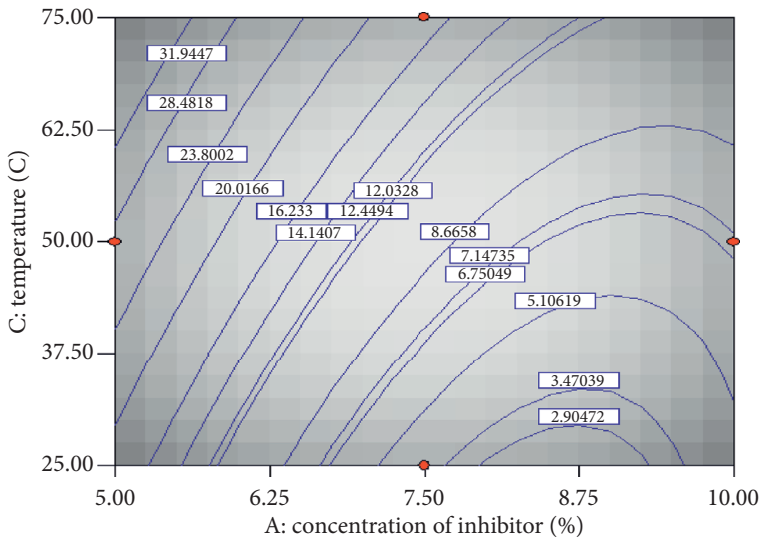

(a)

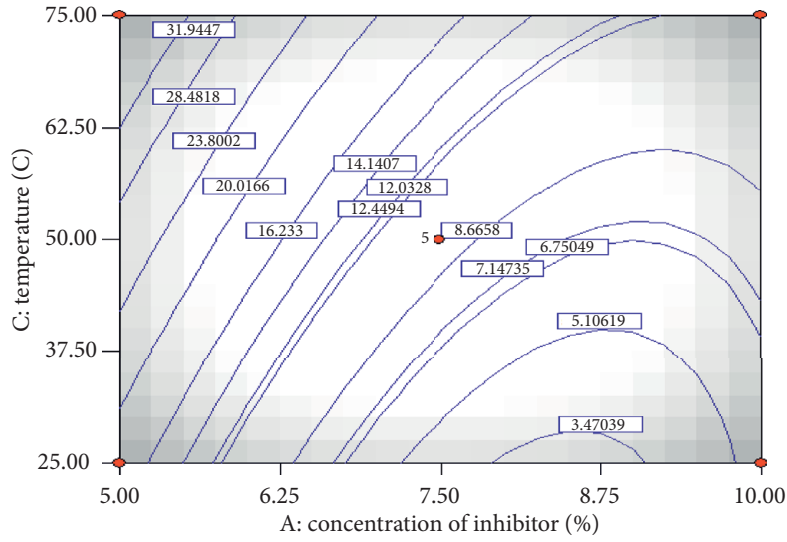

(b)

FIgUre 7: Continued. 


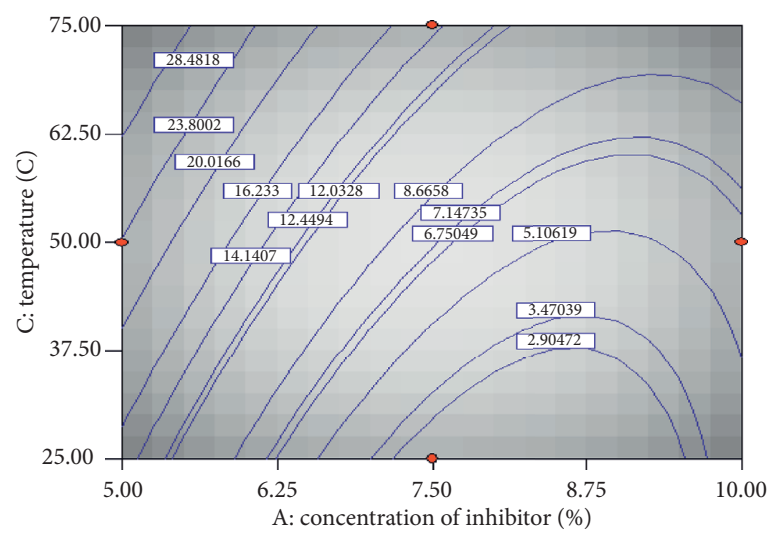

(c)

Figure 7: Contour plot of corrosion rate as a purpose of inhibitor load and temperature at the rotational speeds (a) $250 \mathrm{rpm}$, (b) $200 \mathrm{rpm}$, and (c) $150 \mathrm{rpm}(\mathrm{mL} / \mathrm{Y})$.

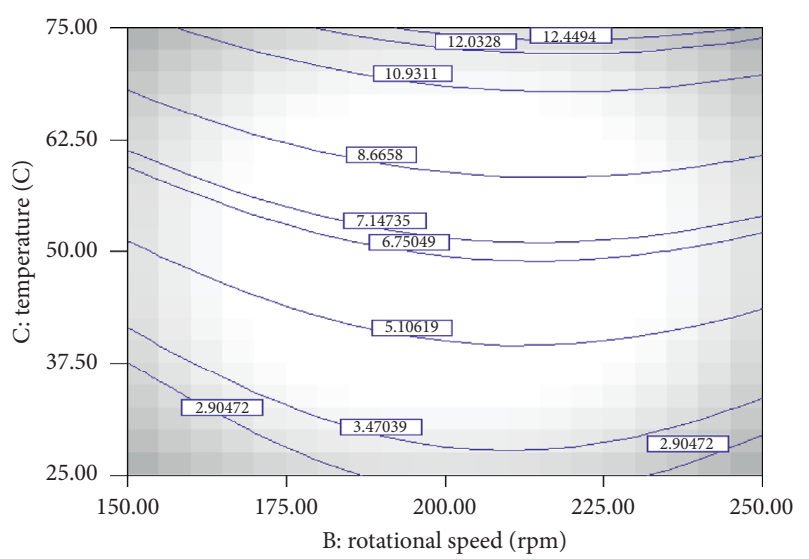

(a)

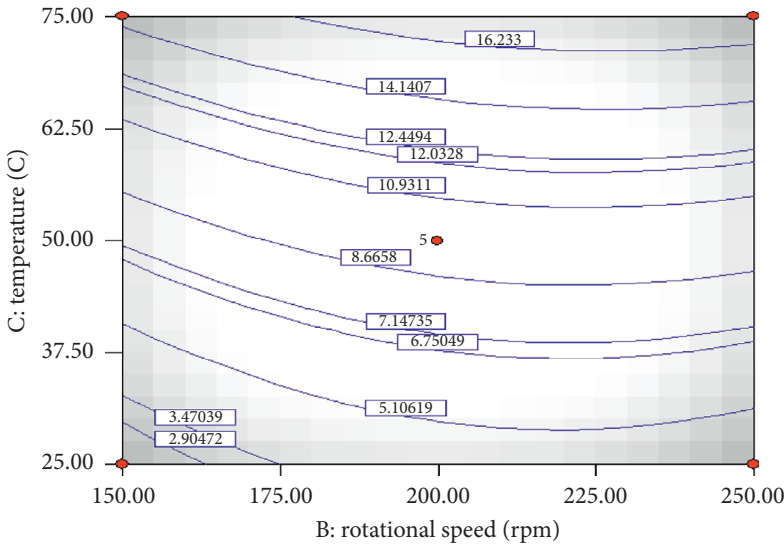

(b)

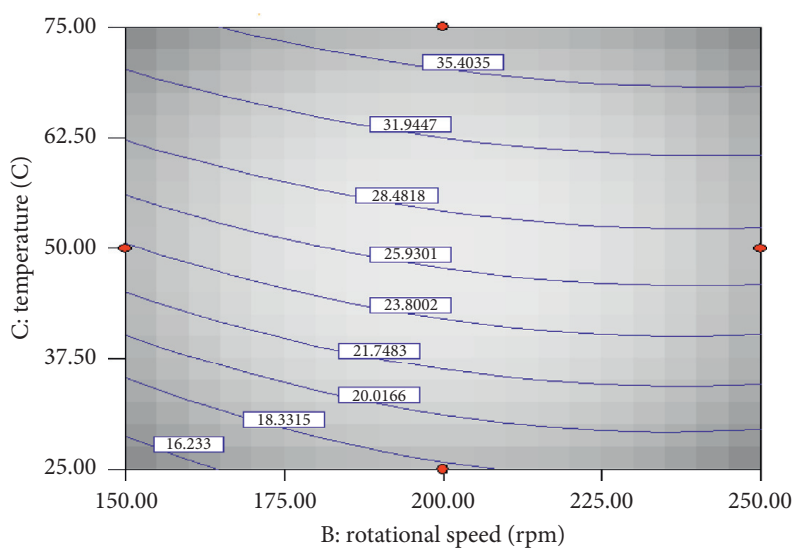

(c)

FiguRE 8: Contour plot of corrosion rate as a purpose of rotational speed and temperature at inhibitor loads (a) $10 \%$, (b) $7.5 \%$, and (c) 5\% $(\mathrm{mL} / \mathrm{Y})$.

plot of residuals in which almost all the residuals fall on a straight line, reflecting that errors were expected to distribute normally, namely, the model exhibits a good stability to predict the response $[62,63]$. 


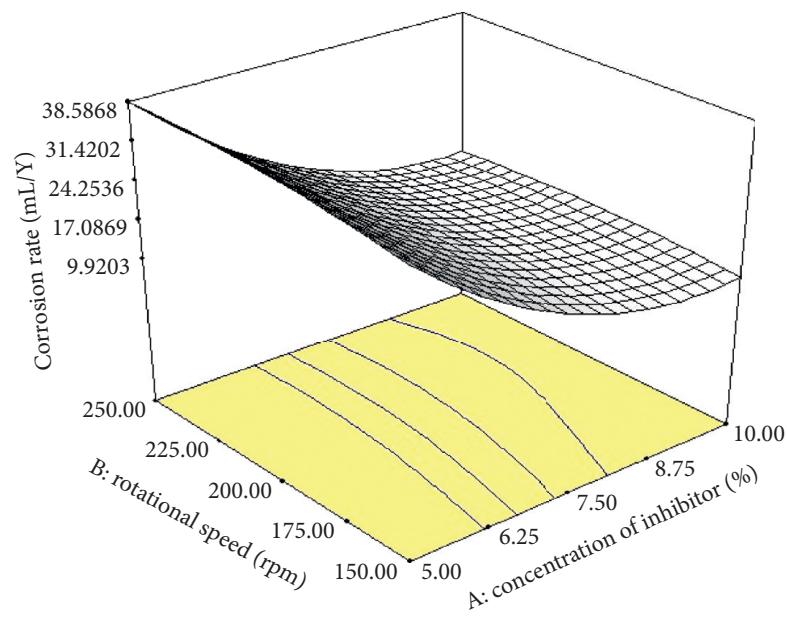

(a)

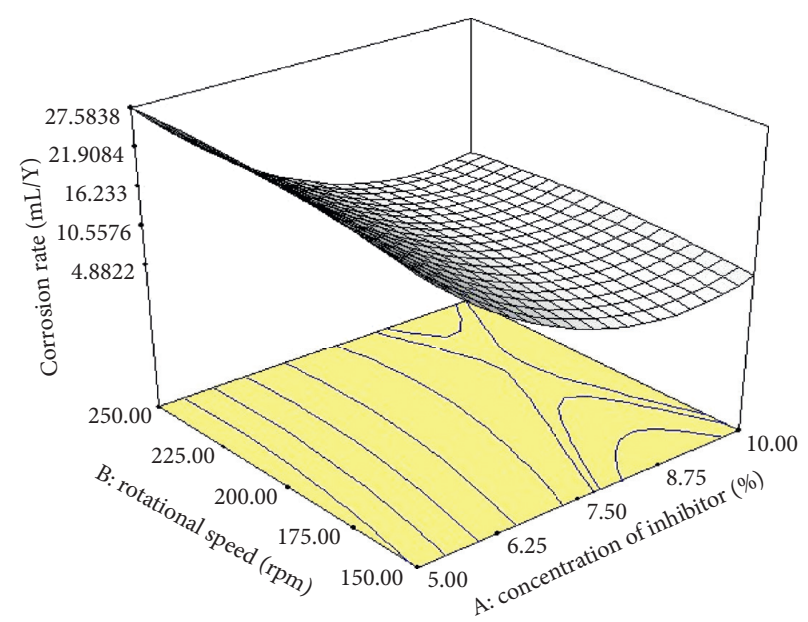

(b)

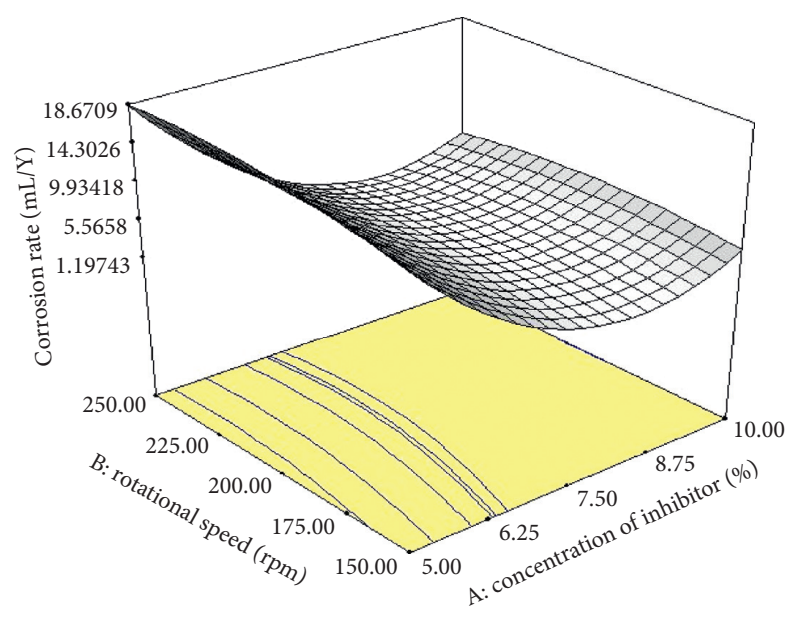

(c)

Figure 9: 3D plot of corrosion rate as a purpose of inhibitor load and rotation speed at temperatures (a) $75^{\circ} \mathrm{C}$, (b) $50^{\circ} \mathrm{C}$, and (c) $25^{\circ} \mathrm{C}$.

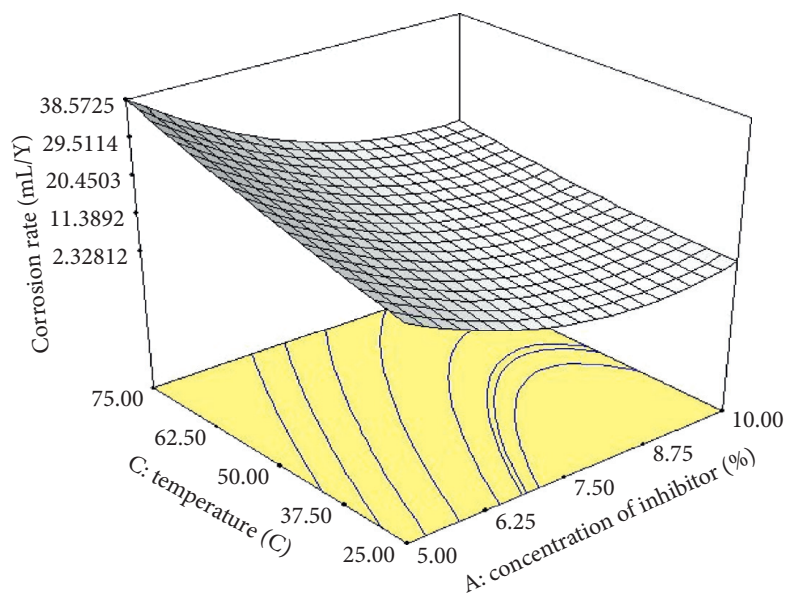

(a)

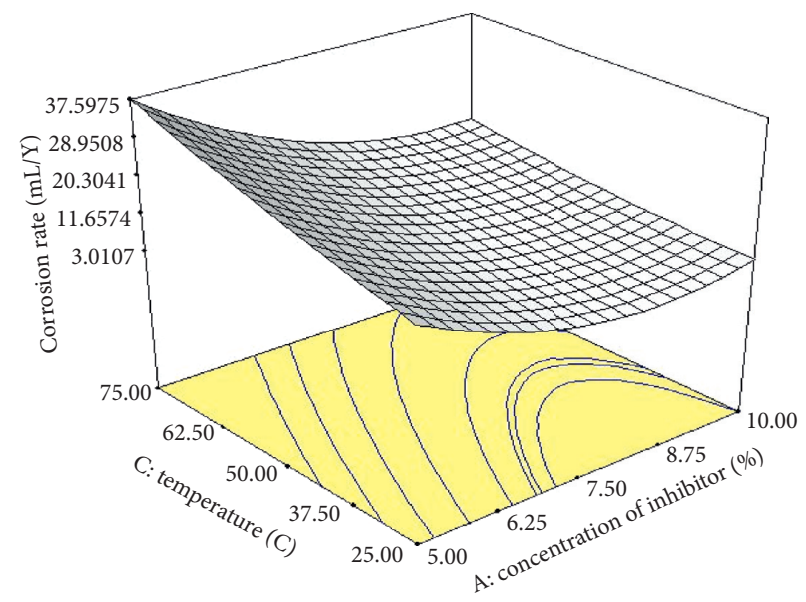

(b)

Figure 10: Continued. 


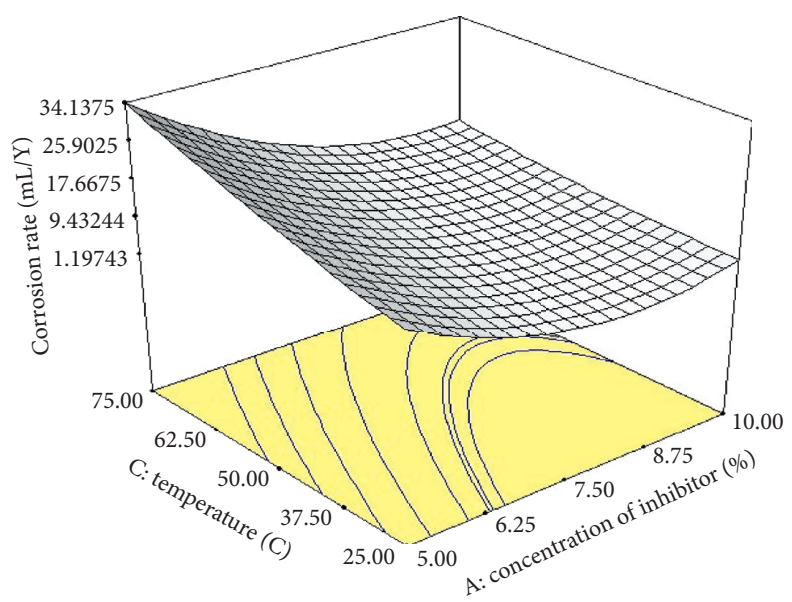

(c)

FIgURE 10: 3D plot of corrosion rate as a purpose of inhibitor load and temperature at rotation speeds (a) $250 \mathrm{rpm}$, (b) $200 \mathrm{rpm}$, and (c) $150 \mathrm{rpm}$.

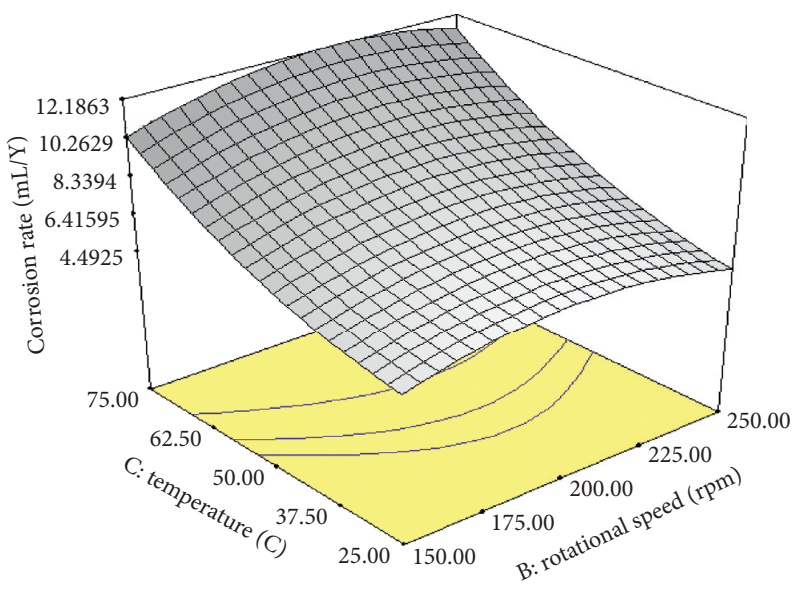

(a)

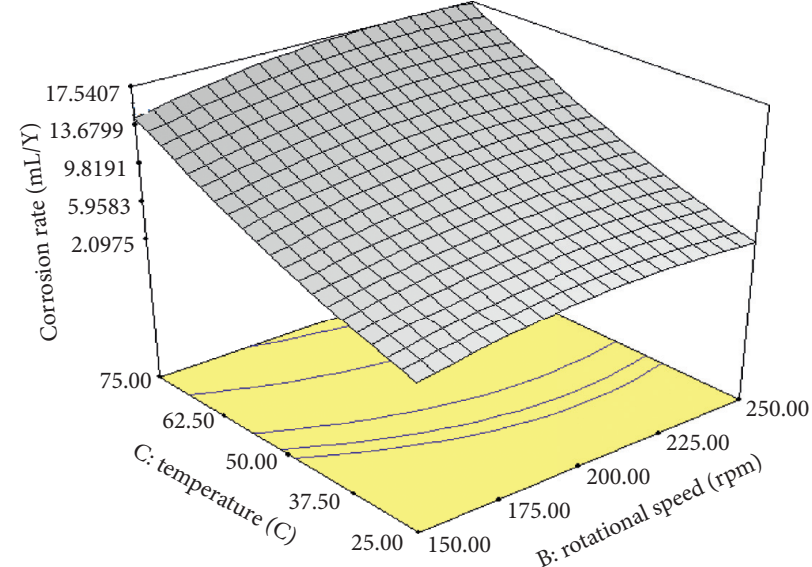

(b)

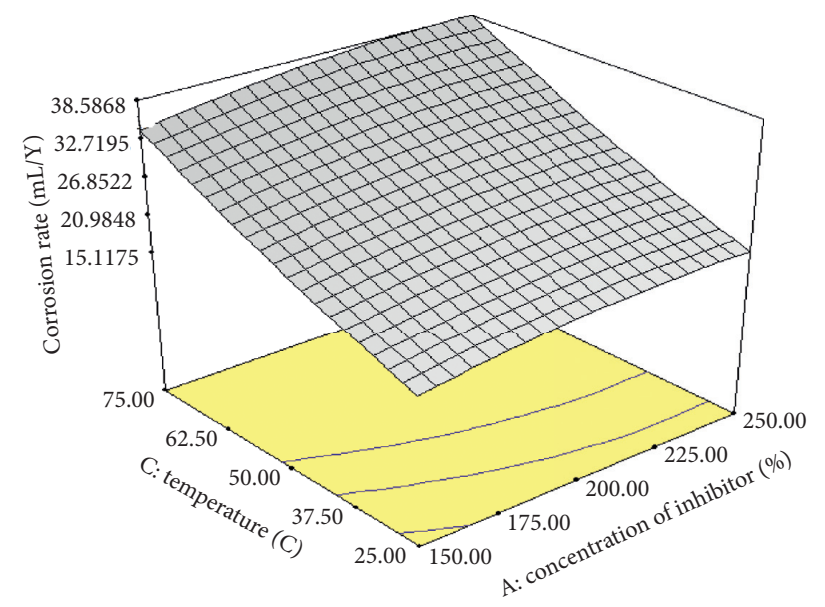

(c)

FIGURE 11: 3D plot of corrosion rate as a purpose of rotational speed and temperature at the inhibitor loads (a) $10 \%$, (b) $7.5 \%$, and (c) $5 \%$. 


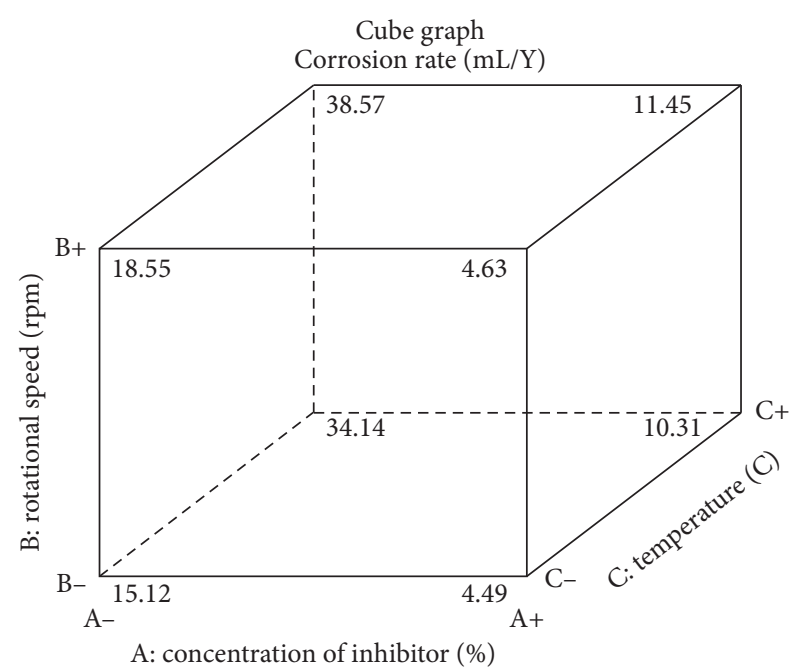

FIGURE 12: 3D plot of corrosion rate as a purpose of inhibitor load, rotation speed, and temperature variables.

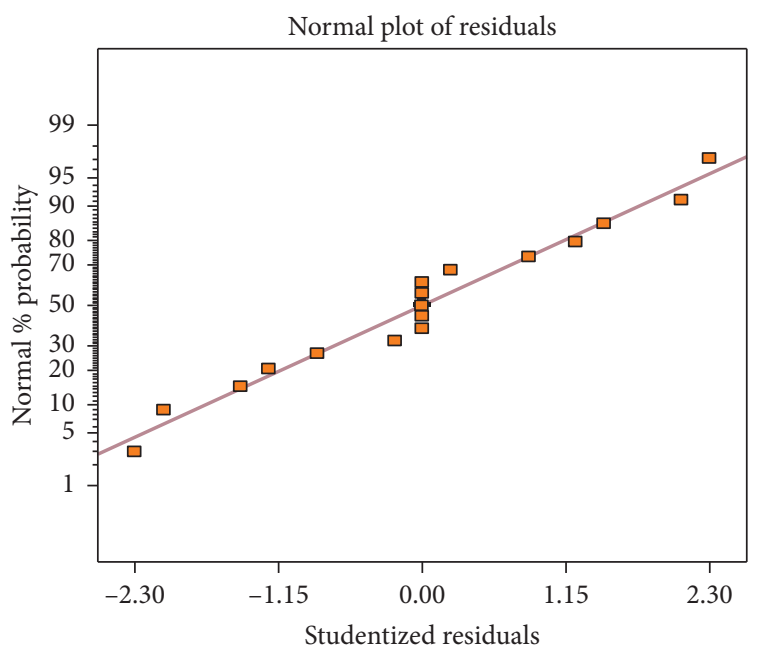

FIgURE 13: Normal plot of error distribution for corrosion rate. follows:

Final equation in terms of actual factors is indicated as

$$
\text { Corrosion rate }(\mathrm{mL} / \mathrm{Y})=+46.40000
$$

(i) Concentration of inhibitor (\%) $=-18.31300$

(ii) Rotational speed $(\mathrm{rpm})=+0.26115$

(iii) Temperature $\left({ }^{\circ} \mathrm{C}\right)=+0.44920$

3.3. Inhibition Efficiency. Figure 14 shows the contour plot of the consequence of inhibitor load and rotation speed on the inhibition efficiency of steel alloy 4130 at different temperatures 25,50 , and $75^{\circ} \mathrm{C}$. Figure 14 shows that, at $25^{\circ} \mathrm{C}$, the inhibition efficiency was increased from 69.32 to $92.87 \%$ with increasing inhibitor concentration from 5 to $10 \%$. Also, increasing rotation speed from 150 to $250 \mathrm{rpm}$ indicates no effect. By increasing temperature to 50 and/or $75^{\circ} \mathrm{C}$, the inhibition efficiency increases with increasing inhibitor concentration and insignificant effect with rotation speed.
Figure 15 shows the contour plot of the consequence of inhibitor concentration and temperature on the inhibition efficiency of steel alloy 4130 at different rotation speeds 150 , 200 , and $250 \mathrm{rpm}$. It is clear that, at $150 \mathrm{rpm}$, the inhibition efficiency was increased from 57.20 to $90.28 \%$ with increasing inhibitor concentration from 5 to $10 \%$. Also, by increasing temperature from 25 to $75^{\circ} \mathrm{C}$, the inhibition efficiency has no effect. The inhibition efficiency has no effect by increasing rotation speed to 200 and/or $250 \mathrm{rpm}$.

Figure 16 shows the contour plot of the consequence of rotation speed and temperature on the inhibition efficiency of steel alloy 4130 at different concentrations of inhibitor 5 , 7.5 , and $10 \%$. It is clear that, at $5 \%$, the inhibition efficiency has no effect with increasing rotation speed from 150 to $250 \mathrm{rpm}$. Also, increasing inhibitor concentration from 5 to $10 \%$ increases the inhibition efficiency from 50.90 to $86.03 \%$. By increasing inhibitor concentration to 7.5 and/or $10 \%$, the inhibition efficiency increases.

Figure 17 shows the 3D plot of the inhibition efficiency of steel alloy 4130 as a purpose of inhibitor load and rotation speed at diverse temperatures 25,50 , and $75^{\circ} \mathrm{C}$. It shows that, at $25^{\circ} \mathrm{C}$, the maximum inhibition efficiency was $62.85 \%$. Also, increasing the temperature from 50 to $75^{\circ} \mathrm{C}$ decreases the inhibition efficiency to 51.13 and $38.78 \%$, correspondingly.

Figure 18 shows the 3D plot of the inhibition efficiency of steel alloy 4130 as a purpose of inhibitor load and temperature at diverse rotation speeds 150,200 , and $250 \mathrm{rpm}$. It shows that, at $150 \mathrm{rpm}$, the maximum inhibition efficiency was $41.91 \%$. Also, increasing the rotation speed from 200 to $250 \mathrm{rpm}$ shows insignificant increase in the inhibition efficiency to 39.75 and $38.78 \%$, respectively.

Figure 19 shows the 3D plot of the inhibition efficiency of steel alloy 4130 as a purpose of rotation speed and temperature at diverse inhibitor concentration 5, 7.5, and 10\%. It shows that, at $5 \%$, the inhibition efficiency was $44.99 \%$. Also, increasing the temperature from 7.5 and $10 \%$ increases the maximum inhibition efficiency to 71.45 and $81.90 \%$, correspondingly.

All the investigational data, composed at the $3 \mathrm{D}$ cubic as given in Figure 20, exposed that the inhibition efficiency which fluctuated from 38.78 to 93.67 (\%) can be produced. The lowest inhibition efficiency, $38.78 \%$, can be obtained at low concentrations of inhibitor and high levels of temperature and rotation speed. On the contrary, the highest inhibition efficiency can be realized at a great concentration of inhibitor and small stages of temperature and rotation speed [64]. However, growing the load of inhibitor leads to increase in the inhibition efficiency, which is desirable. This is attributed to the LI inhibitor, which is well known as the inhibiting agent, since it stable at $<50^{\circ} \mathrm{C}$ and $150 \mathrm{rpm}$. Figure 21 displays the normal plot of residuals in which almost all the residuals fall on a straight line, reflecting that errors were expected to distribute normally, namely, the model exhibits a good stability to predict the response [65].

Final equation in terms of actual factors indicated the following:

Inhibition efficiency $(\%)=-8.27500$ 


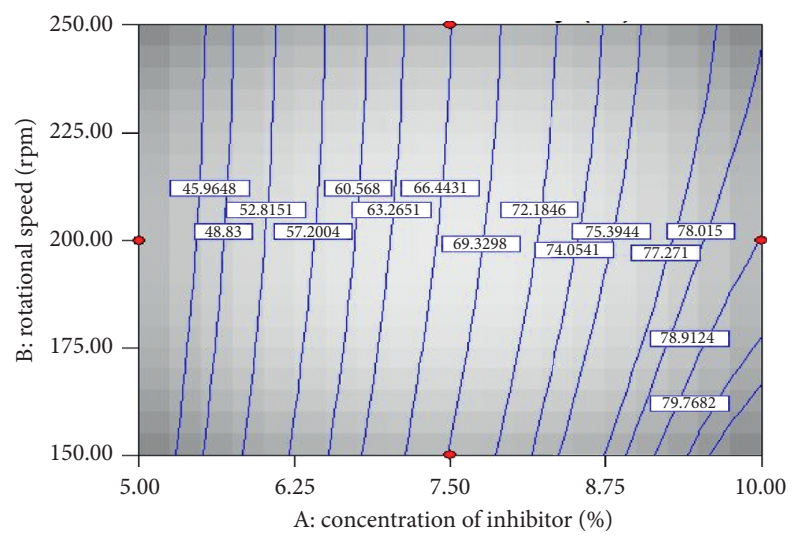

(a)

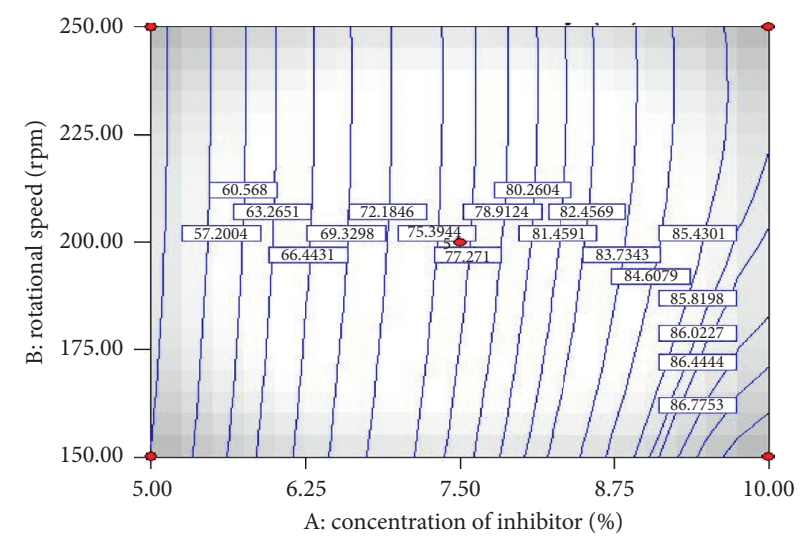

(b)

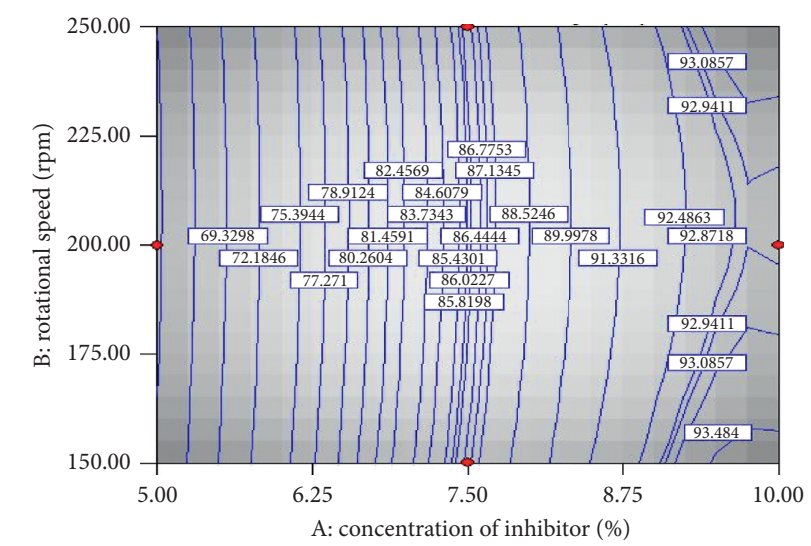

(c)

Figure 14: Contour plot of the inhibition efficiency as a purpose of inhibitor load and rotational speed at the temperatures (a) $75^{\circ} \mathrm{C}$, (b) $50^{\circ} \mathrm{C}$, and (c) $25^{\circ} \mathrm{C}$.

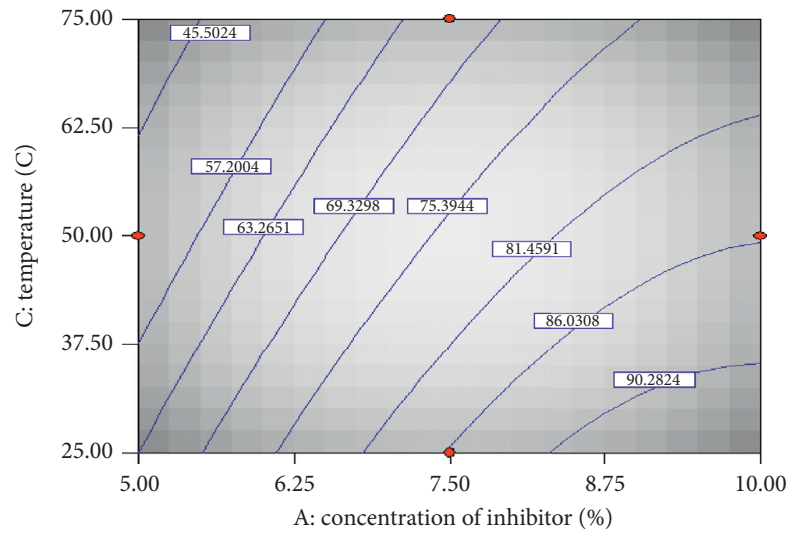

(a)

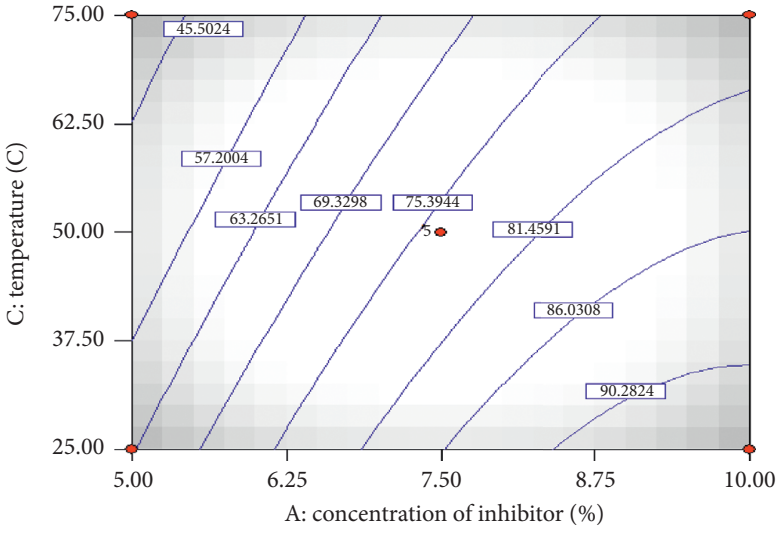

(b)

Figure 15: Continued. 


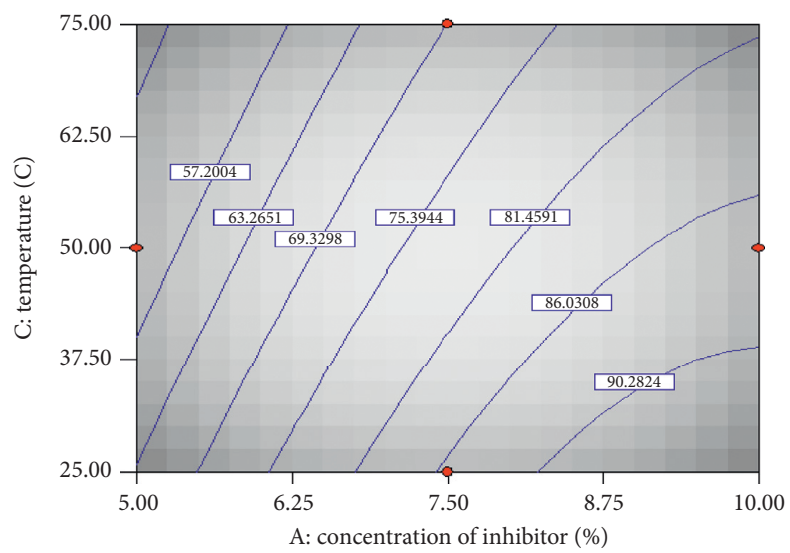

(c)

FIGURE 15: Contour plot of inhibition efficiency as a purpose of inhibitor load and temperature at the rotational speeds (a) $250 \mathrm{rpm}$, (b) $200 \mathrm{rpm}$, and (c) $150 \mathrm{rpm}$.

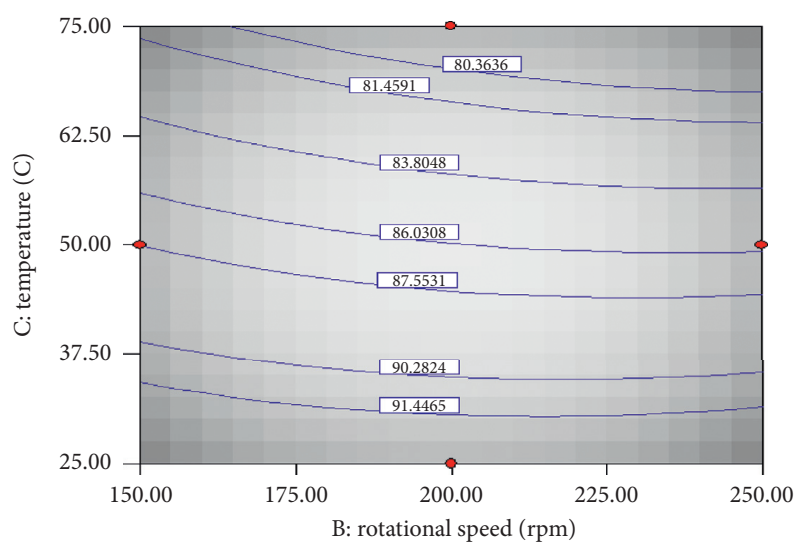

(a)

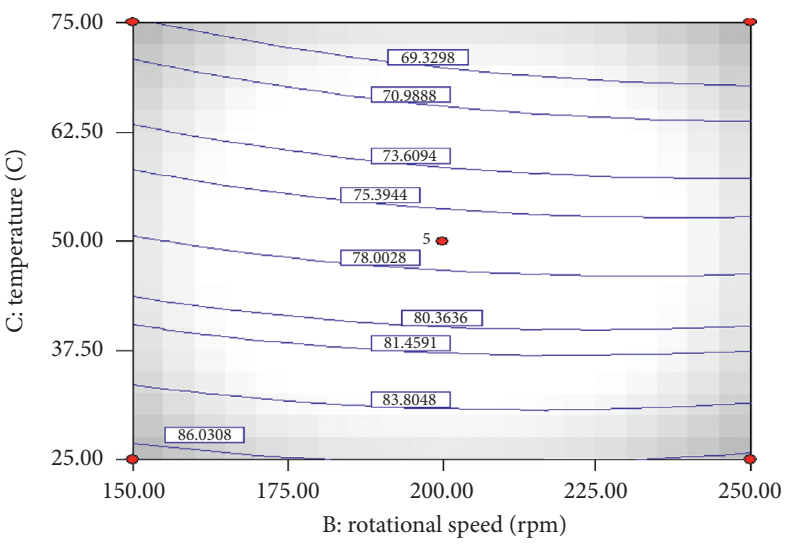

(b)

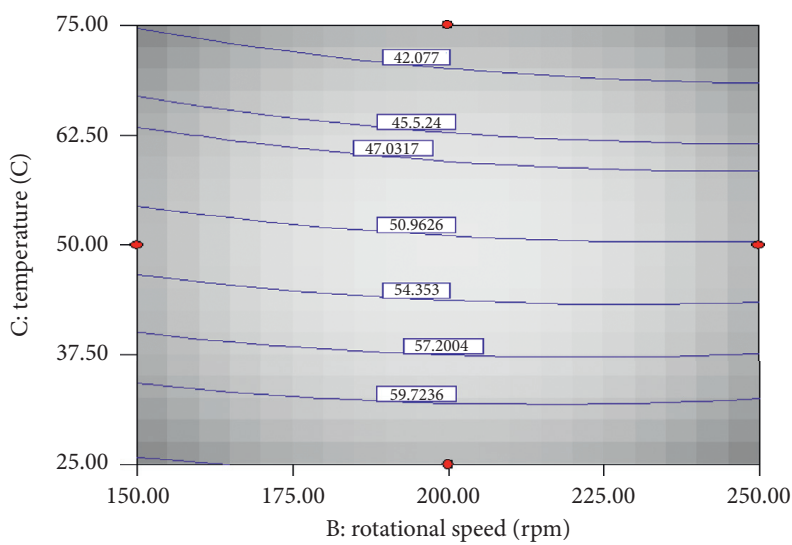

(c)

Figure 16: Contour plot of inhibition efficiency as a purpose of rotational speed and temperature at the inhibitor loads (a) $10 \%$, (b) $7.5 \%$, and (c) $5 \%$.

Concentration of inhibitor $(\%)=+24.30700$

Rotational speed $(\mathrm{rpm})=-0.083375$

Temperature $\left({ }^{\circ} \mathrm{C}\right)=-0.50985$
3.3.1. DFT Results. To examine the consequence of operational constraints on the inhibition efficacy of the inhibitor, the quantum chemical calculations have been achieved. The adsorption mode of action on the metallic outward is 


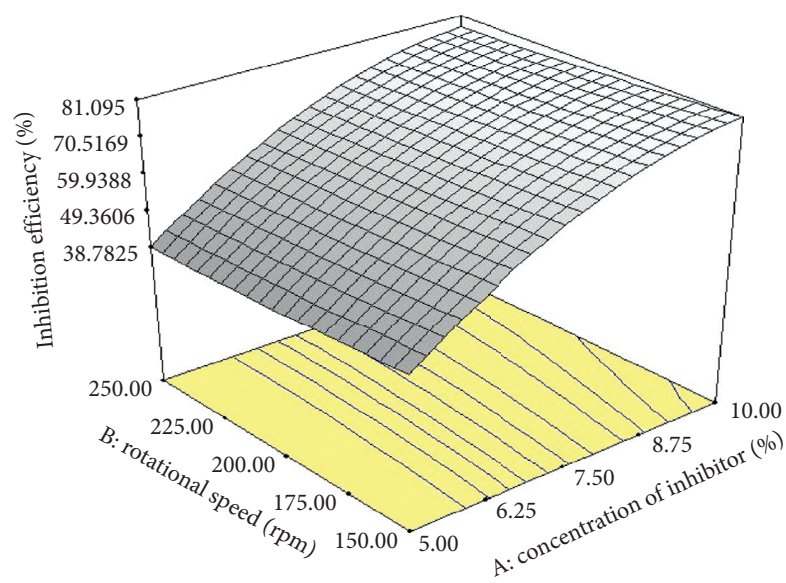

(a)

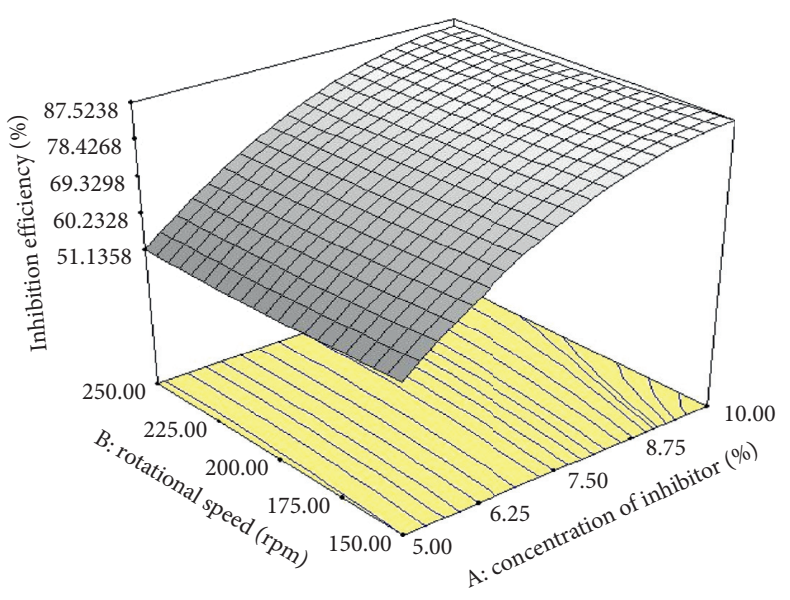

(b)

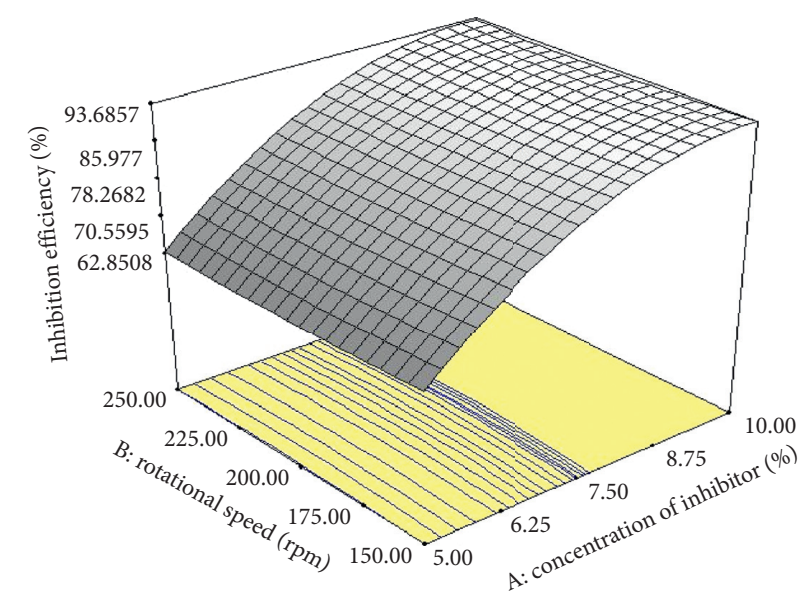

(c)

Figure 17: 3D plot of inhibition efficiency as a function of inhibitor concentration and rotation speed at temperatures (a) $75^{\circ} \mathrm{C}$, (b) $50^{\circ} \mathrm{C}$, and (c) $25^{\circ} \mathrm{C}$.

studied. The geometrical and electronic structure of lawsone is considered by the optimization of their bond angles, dihedral angles, and bond lengths. Figure 22 represents the calculated optimized molecular structure with the minimum energy. The calculated quantum chemical parameters can be used for the inhibition efficiency of inhibitor. Table 5 summarizes the calculated quantum chemical constraints as the energy of the lowermost empty molecular orbital (ELUMO), energy of the maximum engaged molecular orbital (EHOMO), the separation energy (ELUMO$\mathrm{EHOMO}$ ), and $\Delta \mathrm{E}$, representing the meaning of activity, dipole moment $(\mathrm{D})$, chemical potential $(\mu)$, electronegativity $(\chi)$, softness $(\sigma)$, and hardness $(\eta)$. These results indicate that the geometrical structure of lawsone is planner, as shown in Figure 22. Rendering to the frontier molecular orbital theory (FMO), the chemical activity is a purpose of the collaboration amongst HOMO and LUMO planes of the acting types [66]. The $E_{\text {Hомо }}$ designates the capability of the fragment to provide electrons to a suitable receptor through unfilled molecular orbitals, and $\mathrm{E}_{\mathrm{LUMO}}$ designates its aptitude to receive electrons. The higher is the value of $E_{\mathrm{HOMO}}$ of the inhibitor, the superior is its ease of donation electrons to the unoccupied d-orbital of metallic superficial, and the superior is its inhibition efficacy. The lower is the rate of $E_{\mathrm{LUMO}}$, and more is the ability of the fragment to receive electrons (Figure 23). The HOMOLUMO energy gap $(\Delta \mathrm{E})$ method, which is a significant steadiness guide, is practical to progress hypothetical replicas for explanation of the assembly and conformational fences in numerous molecular structures. The minor is the worth of $\Delta \mathrm{E}$, with extra possibility that the complex has inhibition efficacy $[67,68]$. From Table 5 , the molecule has the smallest HOMO-LUMO gap $(\Delta E)$, and hence, the molecule has more inclination to adsorb on the metallic superficial. The dipole moment (D), the primary plagiaristic of the energy regarding a practical electric arena, is castoff to deliberate and vindicate the construction of the molecule [69]. In the literature, there is a deficiency of arrangement on the relationship amongst $\mu$ and inhibition effectiveness [70]. On the contrary, the hypothetical outcomes indicate that there is no noteworthy connection around amongst $\mu$ and inhibition efficacy, referring to 


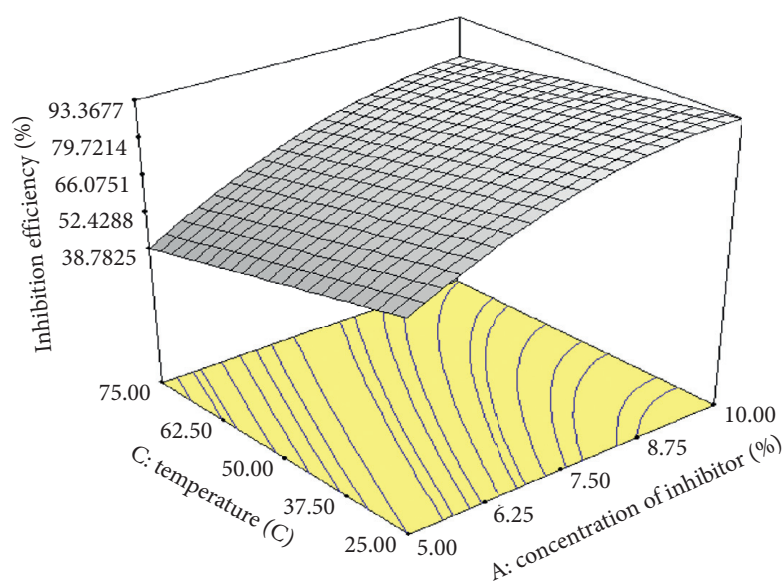

(a)

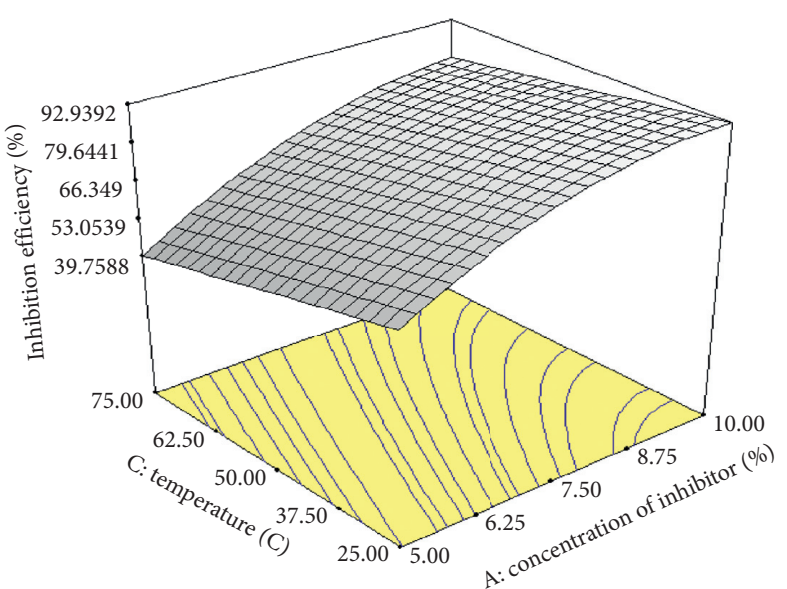

(b)

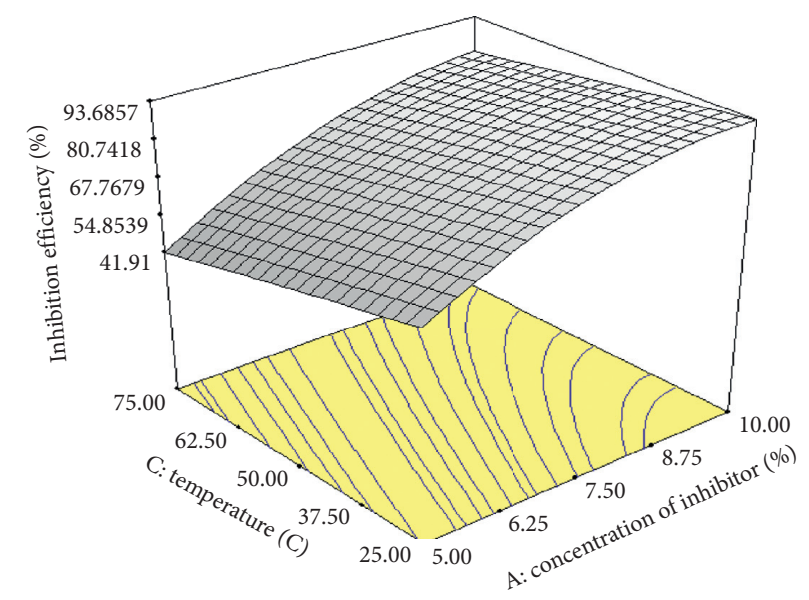

(c)

Figure 18: 3D plot of inhibition efficiency as a function of inhibitor load and temperature at rotation speeds (a) $250 \mathrm{rpm}$, (b) $200 \mathrm{rpm}$, and (c) $150 \mathrm{rpm}$.

Table 5. The absolute softness $(\sigma)$ and hardness $(\eta)$ are significant possessions that quantify individually the constancy and activity of the structural formula. A firm fragment has a great energy hole, and a lenient fragment has a minor energy hole. The lenient fragments are supplementary responsive than the firm ones since they could simply suggest electrons to a receptor. Intended for the humblest transmission of electrons, adsorption could happen at the portion of the molecule where $\sigma$, which is a resident possession, has the maximum rate [71]. In a deterioration arrangement, the inhibitor performs by way of a Lewis base although the metallic surface performs as a Lewis acid, correspondingly. Consequently, it is determined that the inhibitor by means of the uppermost $\sigma$ rate has the maximum capability inhibition effectiveness (Table 5), which is in a decent arrangement with our investigational data. Moreover, our results show that the inhibitor has the lowest $\omega$, and $\chi$ (Table 5) which lead to growth of its contribution capability to the metallic superficial and consequently ornamental its inhibition efficacy. Based on the above results, we can simply conclude that the calculated quantum chemical parameters are confirming that the inhibitor has high inhibition efficacy which decides fit through the investigational explanations. The molecular electrostatic potentials are very supportive in the negative areas that can be observed as nucleophilic cores although areas through positive electrostatic potential are potential electrophilic spots. Additionally, the electrostatic potential types the polarization of the observable electron compactness. Figure 24 shows that the biphenyl moiety and the oxygen atom of hydroxyl group have negative electrostatic potential which resources that these spots are the energetic cores for the requisite to the metallic superficial. The electronic-structure DFT investigates and demonstrated the interactions between the giver and receiver of responsive spots of the corrosion inhibitive particles. We remarkably noticed that the major watersoluble ingredient for the LI, the O-containing lawsone 


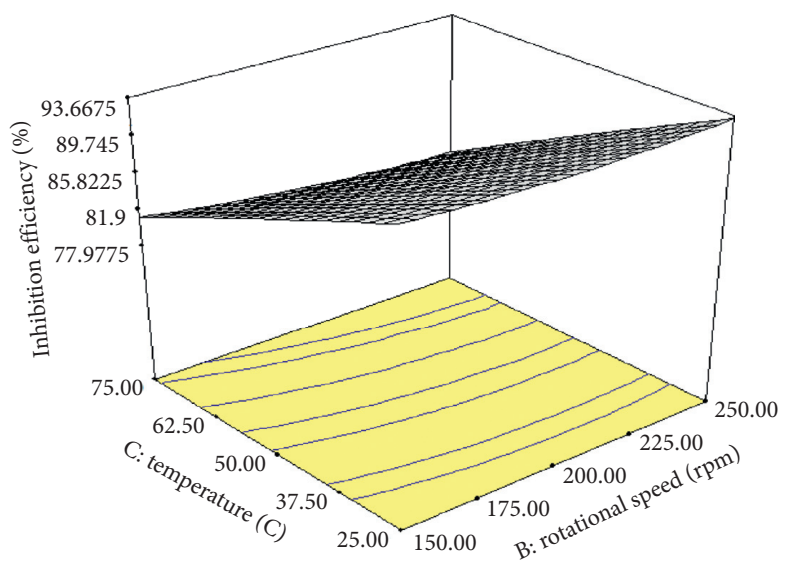

(a)

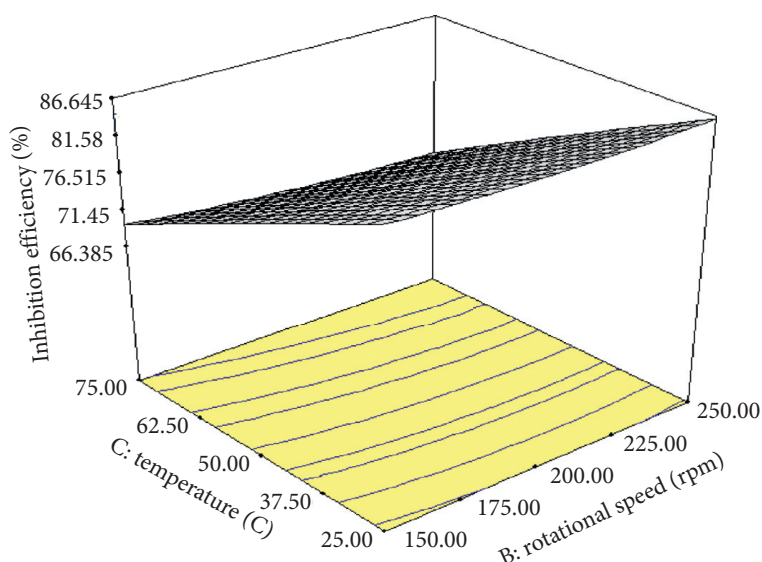

(b)

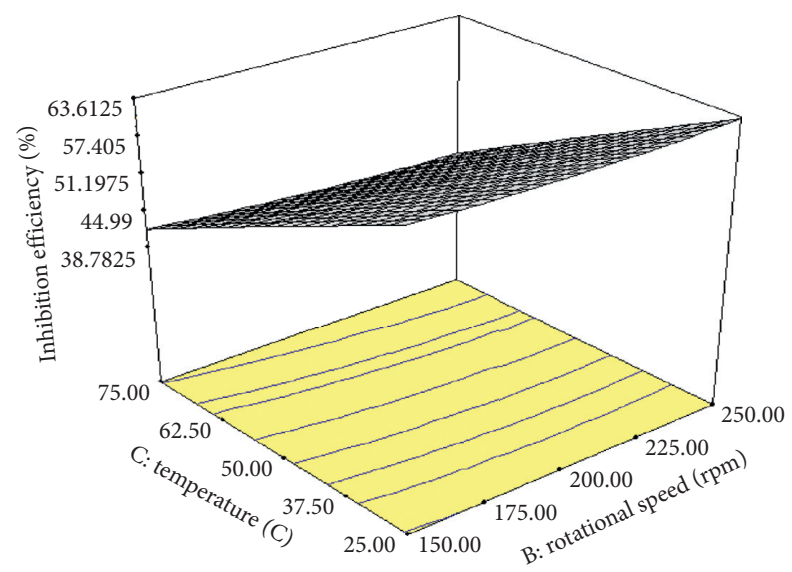

(c)

FigURE 19: 3D plot of inhibition efficiency as a purpose of rotational speed and temperature at the inhibitor loads (a) $10 \%$, (b) $7.5 \%$, and (c) $5 \%$.

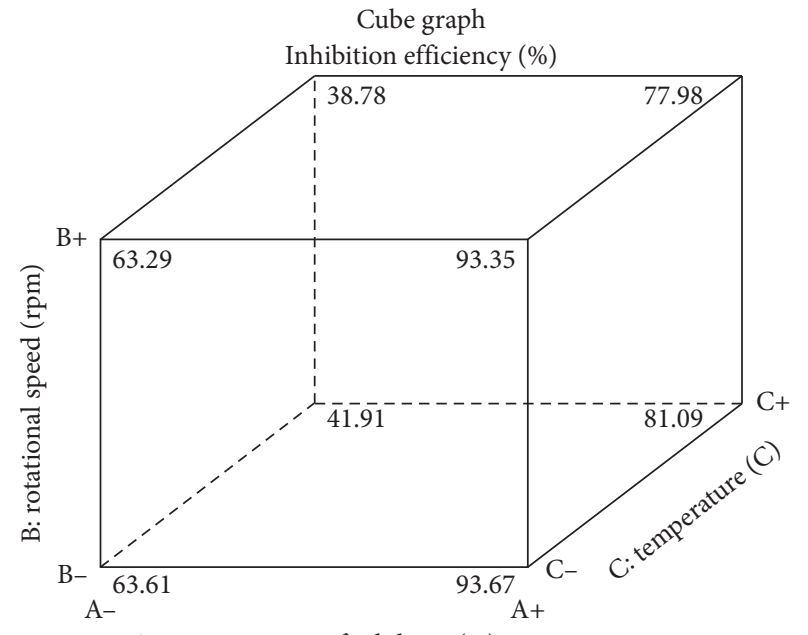

A: concentration of inhibitor (\%)

FIGURE 20: 3D plot of inhibition efficiency as a function of inhibitor concentration, rotation speed, and temperature variables.

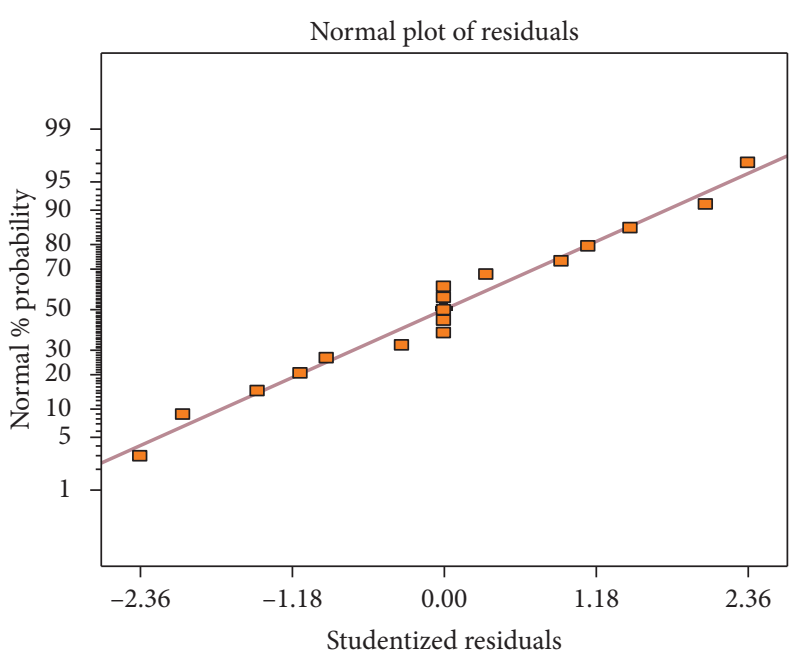

FIgURE 21: Normal plot of error distribution for inhibition efficiency. 


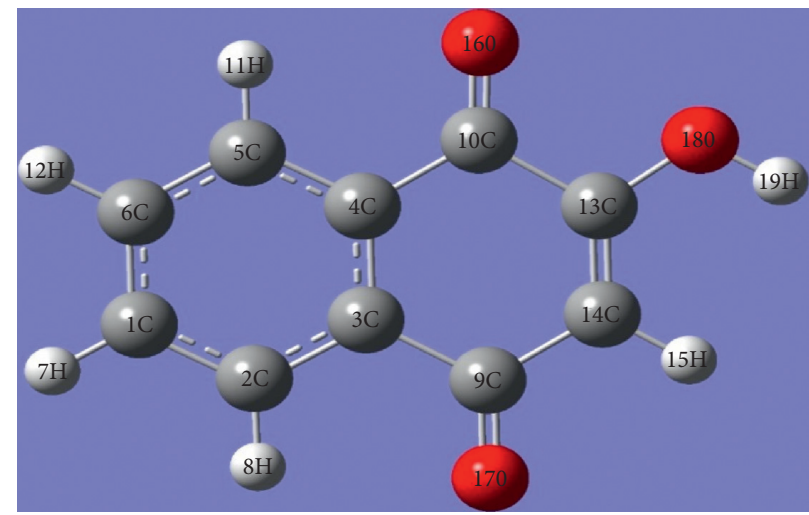

FIgURE 22: The optimized molecular structure of lawsone.

TABle 5: The calculated quantum chemical parameters obtained from DFT calculations of lawsone.

\begin{tabular}{|c|c|c|c|c|c|c|c|c|c|}
\hline$-E_{\text {HOMO }}$ (a.u.) & $-E_{\mathrm{LUMO}}($ a.u. $)$ & $\Delta E$ (a.u.) & DM (Debye) & IP (a.u.) & EA (a.u.) & $\eta$ (a.u.) & $\sigma$ (a.u. $^{-1}$ & $\mu$ (a.u.) & $\chi$ (a.u.) \\
\hline 0.3825 & 0.0677 & 0.3148 & 1.1532 & 0.3825 & 0.0677 & 0.1574 & 6.3532 & 0.2251 & 0.2251 \\
\hline
\end{tabular}

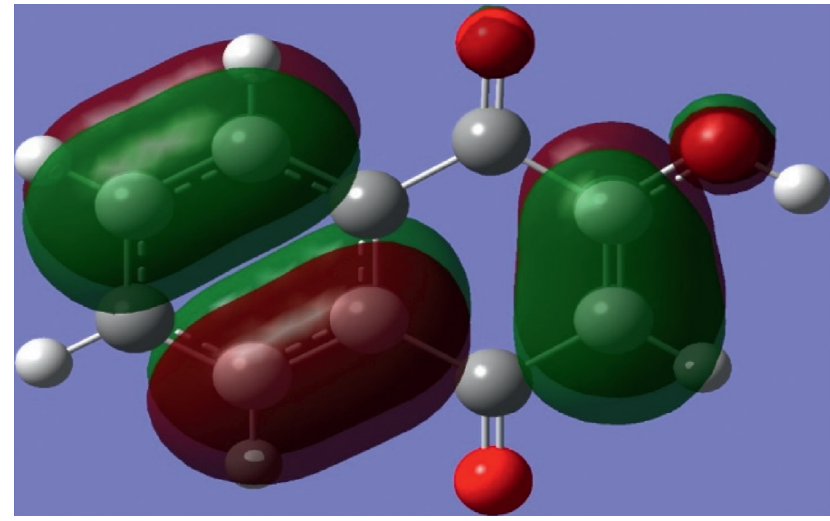

(a)

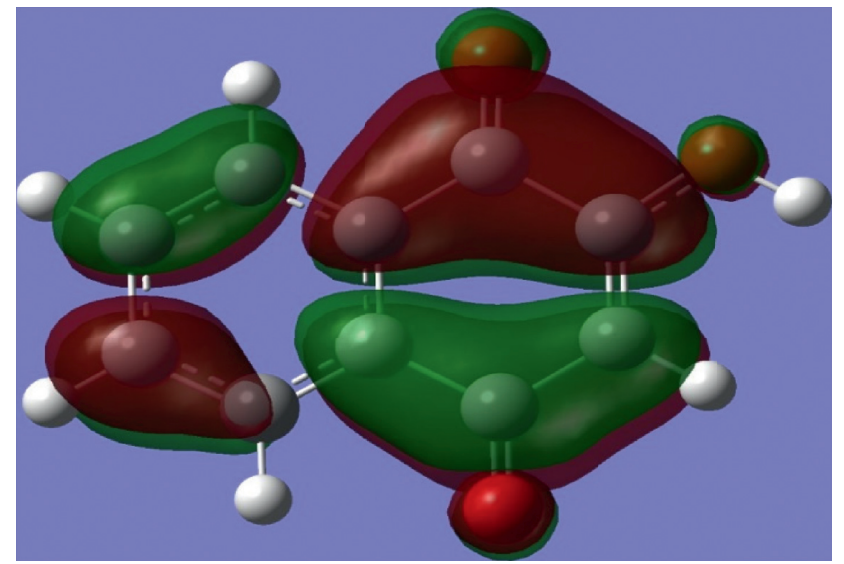

(b)

Figure 23: The HOMO and LUMO of lawsone.

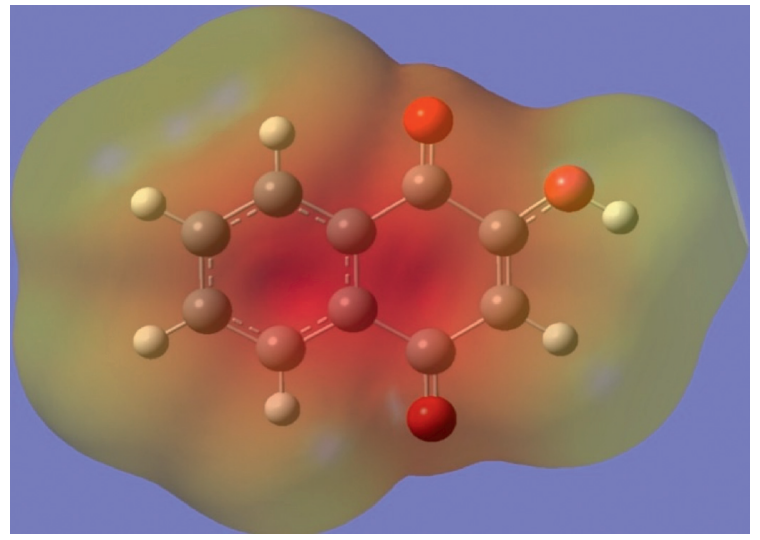

FIgURE 24: The molecular electrostatic potentials of the optimized structure of lawsone. compound which includes a perfect formula, can provide a good corrosion inhibiting effect due to the presence of more than one polar oxygenated center. The potentiality of inhibition was computationally confirmed by DFT theory through the protonation attraction foremost to its probable physisorption and projected adsorption energy.

\section{Conclusions}

The characteristics of corrosion inhibition of green inhibitor based on Lawsonia inermis extract (LI) in 3.5 wt.\% $\mathrm{NaCl}$ solutions on steel alloy 4130 surfaces were estimated by collective investigational and computational approaches. Examinations by EIS designated that, by cumulating the load of LI from 1 to $10 \%$, the protection efficacy pointedly amplified and touched $89.19 \%$. The LI performed as a diverse-type corrosion inhibitor and measured the degree of 
corrosion of equally anodic and cathodic responses. The water-soluble components of LI can interact with steel alloy 4130 superficial over distribution of their lone pair of electrons through empty d-orbital of steel alloy 4130 molecules.

\section{Data Availability}

The data used to support the findings of this study are included within the article.

\section{Conflicts of Interest}

The authors declare that there are no conflicts of interest.

\section{Authors' Contributions}

All authors' contributed equally to this work.

\section{References}

[1] C. Verma, L. O. Olasunkanmi, E. E. Ebenso, M. A. Quraishi, and I. B. Obot, "Adsorption behavior of glucosamine-based, pyrimidine-fused heterocycles as green corrosion inhibitors for mild steel: experimental and theoretical studies," The Journal of Physical Chemistry C, vol. 120, pp. 11598-11611, 2016.

[2] F. M. Alkhrafi, A. M. El-Shamy, and B. G. Ateya, "Comparative effect of tolytrialzole and benzotriazole against sulfide attack on copper," International Journal of Electrochemical Science, vol. 4, pp. 1351-1364, 2009.

[3] C. Verma, H. Lgaz, D. K. Verma, E. E. Ebenso, I. Bahadur, and M. A. Quraishi, "Molecular dynamics and monte carlo simulations as powerful tools for study of interfacial adsorption behavior of corrosion inhibitors in aqueous phase: a review," Journal of Molecular Liquids, vol. 260, pp. 99-120, 2018.

[4] C. Verma, E. E. Ebenso, and M. A. Quraishi, "Ionic liquids as green corrosion inhibitors for industrial metals and alloys," Green Chemistry, IntechOpen Limited, London, UK, 2018.

[5] M. E. Hussein, A. S. El Senousy, W. H. Abd-Elsalam et al., "Roselle seed oil and its nano-formulation alleviated oxidative stress, activated Nrf2 and downregulated m-RNA expression genes of pro-inflammatory cytokines in paracetamol-intoxicated rat model," Records of Natural Products, vol. 14, pp. 1-17, 2019.

[6] M. F. Shehata, A. M. El-Shamy, K. M. Zohdy, E. S. M. Sherif, and S. Zein El Abedin, "Studies on the antibacterial influence of two ionic liquids and their corrosion inhibition performance," Applied Sciences, vol. 10, pp. 1444-1453, 2020.

[7] K. M. Zohdy, A. M. El-Shamy, A. Kalmouch, and E. A. M. Gad, "The corrosion inhibition of $\left(2 Z, 2^{\prime} Z\right)-4,4^{\prime}-(1,2-$ phenylene bis (azanediyl)) bis (4-oxobut-2-enoic acid) for carbon steel in acidic media using DFT," Egyptian Journal of Petroleum, vol. 28, pp. 355-359, 2019.

[8] Y. Morozov, L. M. Calado, R. A. Shakoor et al., "Epoxy coatings modified with a new cerium phosphate inhibitor for smart corrosion protection of steel," Corrosion Science, vol. 159, Article ID 108, 2019.

[9] M. Yeganeh, N. Asadi, M. Omidi, and M. Mahdavian, "An investigation on the corrosion behavior of the epoxy coating embedded with mesoporous silica nanocontainer loaded by sulfamethazine inhibitor," Progress in Organic Coatings, vol. 128, pp. 75-81, 2019.

[10] P. Mahato, S. K. Mishra, M. Murmu, N. C. Murmu, H. Hirani, and P. Banerjee, "A prolonged exposure of Ti-Si-B-C nanocomposite coating in $3.5 \mathrm{wt} . \% \mathrm{NaCl}$ solution: electrochemical and morphological analysis," Surface and Coatings Technology, vol. 375, pp. 477-488, 2019.

[11] M. Murmu, S. K. Saha, N. C. Murmu, and P. Banerjee, "Amine cured double schiff base epoxy as efficient anticorrosive coating materials for protection of mild steel in $3.5 \% \mathrm{NaCl}$ medium," Journal of Molecular Liquids, vol. 278, pp. 521-535, 2019.

[12] E. Alibakhshi, M. Ramezanzadeh, S. A. Haddadi, G. Bahlakeh, B. Ramezanzadeh, and M. Mahdavian, "Persian Liquorice extract as a highly efficient sustainable corrosion inhibitor for mild steel in sodium chloride solution," Journal of Cleaner Production, vol. 210, pp. 660-672, 2019.

[13] S. Nofrizal, A. A. Rahim, B. Saad, P. B. Raja, A. M. Shah, and S. Yahya, "Elucidation of the corrosion inhibition of mild steel in $1.0 \mathrm{M} \mathrm{HCl}$ by catechin monomers from commercial green tea extracts," Metallurgical and Materials Transactions A, vol. 43, pp. 1382-1393, 2012.

[14] M. Banu, R. Joany, and S. Rajendran, "Green approach to corrosion inhibition of mild steel in acid medium by aqueous extract of Pedalium murex L. Leaves," Der Pharma Chemica, vol. 10, pp. 21-28, 2018.

[15] M. Mobin and M. Rizvi, "Polysaccharide from plantago as a green corrosion inhibitor for carbon steel in $1 \mathrm{M} \mathrm{HCl}$ solution," Carbohydrate Polymers, vol. 160, pp. 172-183, 2017.

[16] H. Bourazmi, M. Tabyaoui, L. Hattabi, Y. El Aoufir, and M. Taleb, "Methanolic extract of salvia officinalis plant as a green inhibitor for the corrosion of carbon steel in $1 \mathrm{M} \mathrm{HCl}$," Journal of Materials and Environmental Science, vol. 9, pp. 928-938, 2018.

[17] K. K. Anupama and A. Joseph, "Experimental and theoretical studies on Cinnamomum verum leaf extract and one of its major components, eugenol as environmentally benign corrosion inhibitors for mild steel in acid media," Journal of Bioand Tribo-Corrosion, vol. 4, no. 2, pp. 1-14, 2018.

[18] J. Stephen and A. Adebayo, "Inhibition of corrosion of mild steel in hydrochloric acid solution using akee apple seed extract," Journal of Failure Analysis and Prevention, vol. 18, pp. 350-355, 2018.

[19] A. Saxena, D. Prasad, and R. Haldhar, "Investigation of corrosion inhibition effect and adsorption activities of Achyranthes aspera extract for mild steel in $0.5 \mathrm{M} \mathrm{H}_{2} \mathrm{SO}_{4}$," Journal of Failure Analysis and Prevention, vol. 18, pp. 957968, 2018

[20] E. Alibakhshi, M. Ramezanzadeh, G. Bahlakeh, B. Ramezanzadeh, M. Mahdavian, and M. Motamedi, "Glycyrrhiza glabra leaves extract as a green corrosion inhibitor for mild steel in $1 \mathrm{M}$ hydrochloric acid solution: experimental, molecular dynamics, monte carlo and quantum mechanics study," Journal of Molecular Liquids, vol. 255, pp. 185-198, 2018.

[21] R. S. Mayanglambam, V. Sharma, and G. Singh, "Musa paradisiaca extract as a green inhibitor for corrosion of mild steel in $0.5 \mathrm{M}$ sulphuric acid solution," Portugaliae Electrochimica Acta, vol. 29, pp. 405-417, 2011.

[22] G. Ji, S. Anjum, S. Sundaram, and R. Prakash, "Musa paradisica peel extract as green corrosion inhibitor for mild steel in HCl solution," Corrosion Science, vol. 90, pp. 107-117, 2015. 
[23] M. A. Shaker and H. H. Abdel-Rahman, "Corrosion of copper metal in presence of binary mixtures," American Journal of Applied Sciences, vol. 4, pp. 554-564, 2007.

[24] D. B. Tripathy, M. Murmu, P. Banerjee, and M. A. Quraishi, "Palmitic acid based environmentally benign corrosion inhibiting formulation useful during acid cleansing process in MSF desalination plants," Desalination, vol. 472, Article ID 114128, 2019.

[25] S. Kr. Saha, A. Dutta, P. Ghosh, D. Sukul, and P. Banerjee, "Adsorption and corrosion inhibition effect of Schiff base molecules on the mild steel surface in $1 \mathrm{M} \mathrm{HCl}$ medium: a combined experimental andtheoretical approach," Physical Chemistry Chemical Physics, vol. 17, pp. 5679-5690, 2015.

[26] S. Kr. Saha and P. Banerjee, "Introduction of newly synthesized Schiff base molecules as efficient corrosion inhibitors for mild steel in $1 \mathrm{M} \mathrm{HCl}$ medium: an experimental, density functional theory and molecular dynamics simulation study," Materials Chemistry Frontiers, vol. 2, pp. 1674-1691, 2018.

[27] S. Xia, M. Qiu, L. Yu, F. Liu, and H. Zhao, "Molecular dynamics and density functional theory study on relationship between structure of imidazoline derivatives and inhibition performance," Corrosion Science, vol. 50, pp. 2021-2029, 2008.

[28] G. Gece, "The use of quantum chemical methods in corrosion inhibitor studies," Corrosion Science, vol. 50, pp. 2981-2992, 2008.

[29] N. Khalil, "Quantum chemical approach of corrosion inhibition,” Electrochimica Acta, vol. 48, pp. 2635-2640, 2003.

[30] M. A. Quraishi, R. Sardar, and D. Jamal, "Corrosion inhibition of mild steel in hydrochloric acid by some aromatic hydrazides," Materials Chemistry and Physics, vol. 71, pp. 309-313, 2001.

[31] B. G. Ateya, F. M. Alkharafi, A. M. El-Shamy, A. Y. Saad, and R. M. Abdalla, "Electrochemical desulphurization of geothermal fluids under high temperature and pressure," Journal of Applied Electrochemistry, vol. 39, pp. 383-389, 2009.

[32] V. S. Sastri, "Types of corrosion inhibitor for managing corrosion in underground pipelines," Underground Pipeline Corrosion, Elsevier, Amsterdam, Netherlands, pp. 166-211, 2014.

[33] M. A. Hegazy, M. Abdallah, M. K. Awad, and M. Rezk, “Three novel di-quaternary ammonium salts as novel corrosion inhibitors for API X65 steel pipeline in acidic solution," Corrosion Science, vol. 81, pp. 54-64, 2014.

[34] M. Bruneau, C. M. Uang, and A. Whittaker, Ductile Design of Steel Structures, McGraw Hill, New York, NY, USA, 1997.

[35] D. Kirkland and D. Marzin, "An assessment of the genotoxicity of 2-hydroxy-1,4-naphthoquinone, the natural dye ingredient of henna," Mutation Research/Genetic Toxicology and Environmental Mutagenesis, vol. 537, pp. 183-199, 2003.

[36] S. Rajendran, M. Agasta, R. B. Devi, B. S. Devi, K. Rajam, and J. Jayasundari, "Corrosion inhibition by an aqueous extract of Henna leaves (Lawsonia Inermis L)," Zastita Mater, vol. 50, pp. 77-84, 2009.

[37] S. Elavarasan and M. Gopalakrishnan, "Synthesis, structural analysis, theoretical studies of some lawsone derivatives," Spectrochimica Acta Part A: Molecular and Biomolecular Spectroscopy, vol. 133, pp. 1-6, 2014.

[38] J. A. Cornell and D. C. Montgomery, "Interaction models as alternatives to low-order polynomials," Journal of Quality Technology, vol. 28, pp. 163-176, 1996.

[39] M. Wang, Z. Zhou, Q. Wang, Y. Liu, Z. Wang, and X. Zhang, "Box-behnken design to enhance the corrosion resistance of plasma sprayed Fe-based amorphous coating," Results in Physics, vol. 15, Article ID 102708, 2019.
[40] M. J. Frisch, G. W. Trucks, H. B. Schlegel et al., Gaussian 03, Revision B.01, Gaussian, Inc., Pittsburgh, PA, USA, 2003.

[41] Y. S. Kara, S. G. Sagdinc, and A. Esme, "Theoretical study on the relationship between the molecular structure and corrosion inhibition efficiency of long alkyl side chain acetamide and isoxazolidine derivatives," Protection of Metals and Physical Chemistry of Surfaces, vol. 48, pp. 710-721, 2012.

[42] L. O. Olasunkanmi, I. B. Obot, M. M. Kabanda, and E. E. Ebenso, "Some quinoxalin-6-yl derivatives as corrosion inhibitors for mild steel in hydrochloric acid: experimental and theoretical studies," The Journal of Physical Chemistry C, vol. 119, pp. 16004-16019, 2015.

[43] N. Asadi, M. Ramezanzadeh, G. Bahlakeh, and B. Ramezanzadeh, "Utilizing lemon balm extract as an effective green corrosion inhibitor for mild steel in $1 \mathrm{M} \mathrm{HCl}$ solution: a detailed experimental, molecular dynamics, monte carlo and quantum mechanics study," Journal of the Taiwan Institute of Chemical Engineers, vol. 95, pp. 252-272, 2019.

[44] E. D. Raczyńska, M. Makowski, E. Górnicka, and M. Darowska, "Ab initio studies on the preferred site of protonation in cytisine in the gas phase and water," International Journal of Molecular Sciences, vol. 6, pp. 143-156, 2005.

[45] J. S. de Andrade, M. R. S. Vieira, S. H. Oliveira, S. K. de Melo Santos, and S. L. Urtiga Filho, "Study of microbiologically induced corrosion of 5052 aluminum alloy by sulfate-reducing bacteria in seawater," Materials Chemistry and Physics, vol. 241, Article ID 122296, 2020.

[46] Y. Reda, A. M. El-Shamy, K. M. Zohdy, and A. K. Eessaa, "Instrument of chloride ions on the pitting corrosion of electroplated steel alloy 4130," Ain Shams Engineering Journal, vol. 11, pp. 191-199, 2020.

[47] S. Gudić, L. Vrsalović, M. Kliškić, I. Jerković, A. Radonić, and M. Zekić, "Corrosion inhibition of AA 5052 aluminium alloy in $\mathrm{NaCl}$ solution by different types of honey," International Journal of Electrochemical Science, vol. 11, pp. 998-1011, 2016.

[48] D. Dwivedi, K. Lepkova, and T. Becker, "Carbon steel corrosion: a review of key surface properties and characterization methods," RSC Advances, vol. 7, pp. 4580-4610, 2017.

[49] E. M. Sherif, A. T. Abbas, D. Gopi, and A. M. El-Shamy, "Corrosion and corrosion inhibition of high strength low alloy steel in 2.0 M sulfuric acid solutions by 3-amino-1,2,3triazole as a corrosion inhibitor," Journal of Chemistry, vol. 2014, Article ID 538794, 8 pages, 2014.

[50] E. M. Sherif, A. T. Abbas, H. Halfa, and A. M. El-Shamy, "Corrosion of high strength steel in concentrated sulfuric acid pickling solutions and its inhibition by 3 -amino-5-mercapto1, 2, 3-triazole," International Journal of Electrochemical Science, vol. 10, pp. 1777-1791, 2015.

[51] F. Modiri and H. Savaloni, "A study of the corrosion of stainless steel 304L coated with a $190 \mathrm{~nm}$-thick manganese layer and annealed with nitrogen flux in a 0.4 -mole solution of $\mathrm{H}_{2} \mathrm{SO}_{4}$ at different temperatures," Journal of Theoretical and Applied Physics, vol. 14, pp. 21-35, 2020.

[52] E. A. Adel-Aal, A. A. El-Midany, and H. El-Shall, "Mechanochemical-hydothermal preparation of nano-crystallite hydroxyapatite using statistical design," Materials Chemistry and Physics, vol. 112, pp. 202-207, 2008.

[53] N. O. Obi-Egbedi, I. B. Obot, M. I. El-Khaiary, S. A. Umoren, and E. E. Ebenso, "Computational simulation and statistical analysis on the relationship between corrosion inhibition efficiency and molecular structure of some phenanthroline derivatives on mild steel surface," International Journal of Electrochemical Science, vol. 6, pp. 5649-5675, 2011. 
[54] K. Khaled, "Studies of iron corrosion inhibition using chemical, electrochemical and computer simulation techniques," Electrochimica Acta, vol. 55, pp. 6523-6532, 2010.

[55] N. Kovačević and A. Kokalj, "Analysis of molecular electronic structure of imidazole- and benzimidazole-based inhibitors: a simple recipe for qualitative estimation of chemical hardness," Corrosion Science, vol. 53, pp. 909-921, 2011.

[56] S. K. Saha, P. Ghosh, A. Hens, N. C. Murmu, and P. Banerjee, "Density functional theory and molecular dynamics simulation study on corrosion inhibition performance of mild steel by mercapto-quinoline Schiff base corrosion inhibitor," Physica E: Low-Dimensional Systems and Nanostructures, vol. 66, pp. 332-341, 2015.

[57] A. Y. Musa, R. T. Jalgham, and A. B. Mohamad, "Molecular dynamic and quantum chemical calculations for phthalazine derivatives as corrosion inhibitors of mild steel in $1 \mathrm{M} \mathrm{HCl,"}$ Corrosion Science, vol. 56, pp. 176-183, 2012.

[58] S. John, M. Kuruvilla, and A. Joseph, "Adsorption and inhibition effect of methyl carbamate on copper metal in $1 \mathrm{~N}$ $\mathrm{HNO}_{3}$ : an experimental and theoretical study," RSC Advances, vol. 3, pp. 8929-8938, 2013.

[59] S. K. Saha, M. Murmu, N. C. Murmu, and P. Banerjee, "Evaluating electronic structure of quinazolinone and pyrimidinone molecules for its corrosion inhibition effectiveness on target specific mild steel in the acidic medium: a combined DFT and MD simulation studies," Journal of Molecular Liquids, vol. 224, pp. 629-638, 2016.

[60] J. Fu, H. Zang, Y. Wang, S. Li, T. Chen, and X. Liu, "Experimental and theoretical study on the inhibition performances of quinoxaline and its derivatives for the corrosion of mild steel in hydrochloric acid," Industrial \& Engineering Chemistry Research, vol. 51, pp. 6377-6386, 2012.

[61] A. Dutta, S. K. Saha, P. Banerjee, and D. Sukul, "Correlating electronic structure with corrosion inhibition potentiality of some bis-benzimidazole derivatives for mild steel in hydrochloric acid: combined experimental and theoretical studies," Corrosion Science, vol. 98, pp. 541-550, 2015.

[62] S. D. Accelrys, Software Inc., 2009.

[63] V. Srivastava, J. Haque, C. Verma et al., "Amino acid-based imidazolium zwitterions as novel and green corrosion inhibitors for mild steel: experimental, DFT and MD studies," Journal of Molecular Liquids, vol. 244, pp. 340-352, 2017.

[64] Z. Salarvand, M. Amirnasr, M. Talebian, K. Raeissi, and S. Meghdadi, "Enhanced corrosion resistance of mild steel in $1 \mathrm{M} \mathrm{HCl}$ solution by trace amount of 2-phenyl-benzothiazole derivatives: experimental, quantum chemical calculations and molecular dynamics (MD) simulation studies," Corrosion Science, vol. 114, pp. 133-145, 2017.

[65] A. Lalitha, S. Ramesh, and S. Rajeswari, "Surface protection of copper in acid medium by azoles and surfactants," Electrochimica Acta, vol. 51, pp. 47-55, 2005.

[66] D. Q. Zhang, L. W. Gao, and G. D. Zhou, "Inhibition of copper corrosion in aerated hydrochloric acid solution by heterocyclic compounds containing a mercapto group," Corrosion Science, vol. 46, pp. 3031-3040, 2004.

[67] G. Gao and C. Liang, "Electrochemical and DFT studies of $\beta$-amino-alcohols as corrosion inhibitors for brass," Electrochimica Acta, vol. 52, pp. 4554-4559, 2007.

[68] G. Gece and S. Bilgiç, "Quantum chemical study of some cyclic nitrogen compounds as corrosion inhibitors of steel in $\mathrm{NaCl}$ media," Corrosion Science, vol. 51, pp. 1876-1878, 2009.

[69] A. Stoyanova, G. Petkova, and S. D. Peyerimhoff, "Correlation between the molecular structure and the corrosion inhibiting effect of some pyrophthalone compounds," Chemical Physics, vol. 279, pp. 1-6, 2002.

[70] S. Martınez, "Inhibitory mechanism of mimosa tannin using molecular modeling and substitutional adsorption isotherms," Materials Chemistry and Physics, vol. 77, pp. 97-102, 2003.

[71] A. H. Atta, N. H. Mohamed, S. M. Nasr, and S. M. Mouneir, "Phytochemical and pharmacological studies on convolvulus fatmensis ktze," Journal of Natural Remedies, vol. 7, pp. 109-119, 2007. 